\title{
What Can Technology Offer the Future Fisheries Scientist - Possibilities for Obtaining Better Estimates of Stock Abundance by Direct Observations
}

\author{
Olav Rune Godø \\ Institute of Marine Research, P. O. Box 1870 \\ N-5024 Bergen, Norway
}

\begin{abstract}
The need for quality data from fisheries abundance surveys for the rational management of the world's major fisheries resources has been steadily increasing. The limitation of fish resources and the heavy exploitation pressure put on these resources have forced the industry to change and adjust strategy accordingly and to develop new and more efficient fishing gears and fish finding instruments. Earlier, the assessment and management was based on models which utilized data primarily from the fishing fleet. However, the lack of continuity and stability caused by the continuously changing fishing techniques, creates uncertainty for the management decisions based on catch data.
\end{abstract}

The experience from 30 to 40 years of scientific surveys has shown that this source of information also involves a great deal of uncertainty. The need for improvements in survey methodology is crucial for improving assessments of all major fish stocks. The great limitation in improving the reliability of survey based abundance estimates is the variability and inconsistency of the data collected at sea. In the development of acoustic surveys the policy has been to continuously improve the technical equipment. New technology has been introduced when sufficient calibration exists so as not to seriously disrupt the time series. In contrast, standardization has been the most dominant philosophy in bottom trawl survey history. Therefore new technology and information has been difficult to implement in survey equipment and procedures.

The main challenge in the next century will be to update survey methodology with state-of-the-art technology. Further, combining information from different sources will be the greatest challenge for new research, for example combining data from acoustic and bottom trawl surveys. Underwater observation technology (video, laser, electronic tags, automatic underwater vehicles etc.) will greatly improve our insight on the efficiency and variability of standard survey methodologies. A major difficulty will be to distinguish between and make decisions on the need for additional monitoring and/or modelling based on new technology and information.

Keywords: fish behaviour, catchability, management, stock assessment, surveys, technology

\section{Introduction}

The growing human population has increased the pressure on the commercially most important fish stocks. The total world catches has leveled out during the last decade, and a high percentage of the most productive fish stocks are categorized as depleted or overexploited (see e.g. FAO, 1997). At present, a substantial increase in world catches is unobtainable without improved management, i.e. sustainable harvesting of already exploited resources. Sound and sustainable management depends on a high level of knowledge and, most importantly, reliable monitoring of the state of the stocks through scientific surveys.

The use of scientific abundance survey data is an important aspect for assessing the present state of a stock for most of the commercially important species. The quality of survey data has in most cases not yet been considered good enough for a "stand alone" assessment. Normally, indices of abundance are used to tune VPA or other types of catch-at-age models (see e.g. Hilborn and Walters, 1992). In such models, uncertainties in the final assessment are due to the inherent uncertainties in all the model inputs. 
When stock management fails, lack of knowledge and understanding of the ecosystem dynamics and environmental influences have often been presented as the main explanations (e.g. cod in the Barents Sea, late-1980s and off Newfoundland in the beginning of the, 1990s, see Jakobsson et al., 1994). In many areas, therefore, development of multi-species or ecosystem models has been given great attention during the last decades (Laevastu and Larkins, 1981; Bogstad and Tjelmeland, 1993; Anon., MS 1997). Such models need quantitative information from surveys on relationships between species and size groups to be able to model interactions. Normally, survey data are presented and used as indices of abundance and not as absolute measures of stock size or composition (Doubleday and Rivard, 1981). In such cases, it is assumed that surveys reflect relative changes fairly accurately.

The knowledge and information on survey limitations for supplying absolute information on relationships between size groups or species has substantially increased recently (see e.g. Walsh et al., 1993; Fernø and Olsen, 1994). Such information has been used to improve survey methodology and to point to new areas of future research. However, any development in management, single species or advanced ecosystem modelling, is presently strongly limited by the quality of the observations obtained from the underwater reality.

At the United Nations conference on environment and development in Rio de Janeiro, the focus was on the human impact on bio-diversity (UNCED, 1992). Further, the FAO focus on the precautionary approach in fisheries (FAO, 1995a, b), stresses the importance and need for improved monitoring and assessment of marine resources effects in the future (see also West, 1998). Such monitoring will put new demands on future scientific surveys related to inter-specific representativeness of survey samples.

When survey methods were developed, basic knowledge on underwater sampling gear performance as well as fish behaviour in the catching process was limited. Rigid survey standardization compensated for all the problems associated with catch and effort data from the trawler fleet, and the strategy was a tremendous step forward on the way to obtain quality data on fish stock abundance and composition. The instrumentation for direct observation and monitoring of underwater phenomenon was very limited. Thus survey methodology was associated with a blindfolded sampling technique which needed rough assumptions related to efficiency of trawls and stability of fish behaviour and distribution. Today many of the assumption can be verified or compensated for through better observational methods and survey designs. The resistance against using such knowledge is normally strong due to fear of corrupting a long time series.

In this paper, the current "state-of-the-art" survey methodologies will be considered in an historic perspective. The potential of utilizing new techniques in future surveys is discussed. Implementation of new technologies and techniques in existing surveys is given specific attention.

\section{Observation Methods and Their Limitations}

Our inability to directly observe underwater reality greatly limits our ability to measure the status of fish stocks. Estimates of stock abundance are for most commercially important stocks obtained from standardized surveys. Bottom trawl and acoustic surveys are most common, followed by different static gears, such as pots, gillnets and long lines. Instrumentation and methods have emerged in recent years that have enlightened the limitations in present standard survey methodology.

\section{Abundance Surveys in a Historic Perspective}

The idea of using dedicated effort to measure and monitor fish abundance is old. At the end of last century, a dispute on the possibility of reducing fish abundance by fishing was tested by means of a trawling experiment in Scottish coastal waters (Fulton, 1898). However, as long as an expansion in the commercial fleet was possible, effort was more focused on exploring for and exploiting new resources. Nevertheless, causes of variation in exploited fish stocks were put on the agenda at the beginning of the century due to fluctuations in landings of some of the large oceanic stocks (Hjort, 1914). After World War 
II serious signs of stock depletion in many areas raised concern on the effect fishing had on fish populations. Development of population dynamic models (Beverton and Holt, 1957), initiated systematic monitoring of many important fish stocks. Under the international organizations like ICNAF (International Commission for the Northwest Atlantic Fisheries) and ICES (International Council for Exploration of the Sea) for such monitoring started at the end of the 1950s (see e.g. Anon., MS 1959, Anderson, 1998). The use of catch data to establish the historical trends of stocks and catch per unit of effort (CPUE) to evaluate the present state of stocks was found to be problematic. The efficiency of the commercial trawling effort improved continuously and the fishermen's strategy changed continuously to optimize profit. Furthermore, migratory and distribution patterns will often make the assumptions for a standard CPUE analysis invalid (Ulltang, 1977). Consequently, analysis of CPUE data from the commercial fleets may produce misleading estimates of abundance trends.

The philosophy of standardized surveys is that they minimize the variability typical for commercial fisheries data and thus generate more consistent indices of stock abundance (Doubleday and Rivard, 1981). Routine bottom trawl surveys were set up around the beginning of the, 1960s, first in East Coast American waters, and later in all the productive fishing areas for demersal fish (see e.g. Doubleday and Rivard, 1981; Alton, 1986; Gundersen, 1993; Pauly, 1988).

The development of acoustic methods for monitoring the distribution and density of fish in the post World War II period opened the way for its use for stock assessments (Dragesund and Olsen, 1965). The method is mainly used for pelagic fish but has also wide application for semi-pelagic gadoids (Simmonds and McLennan, 1996; God $\varnothing$ and Wespestad, 1993). For demersal species distributed in areas where trawling is impossible and acoustic method do not apply, surveys with static gears have been tried (see e.g. Quin et al., 1985; Hovgård and Riget, 1992; Engås and Løkkeborg, 1994; Somerton and Kikkawa, 1995).

The basic assumption in bottom trawl survey methodology has until now been that a rigid standardization of equipment, procedures and routines minimizes the effects of the variable, unknown, and unseen underwater reality. To what extent this approach reduces variability sufficient to make them trustworthy can only be tested through long experience or through improved understanding of the underwater reality by direct observation. The basic approach to trawl surveys has not changed fundamentally in its 100-year history. Acoustic surveys, in contrast, have been characterized by a tremendous development in equipment, and technical improvements have continuously been implemented because the positive effect on survey results have been obvious, and the consistency of the time series has been maintained through calibration procedures (Foote et al., 1987; Simmonds et al., 1992).

\section{Commercial CPUE}

Yearly commercial CPUE estimates are often considered to be a time series of abundance indices similar to those produced by standard routine surveys. For example, in tuning procedures the weight given this series as compared to survey series is estimated based on their ability to reflect past variation in stock abundance. With the establishment of a long time series of survey indices, commercial CPUE indices normally lose their importance in assessments. Often the data obtained from the fleet are pooled with resulting loss of detail on sources of fleet variability. The equipment and strategies varies within the fleet and over time, which without documentation is impossible to analyze. The calculation procedures for estimating the CPUE index are thus based on pooling and averaging grounded on very rough assumptions. Due to the steadily increasing efficiency of the fleet and its ever changing fishing strategy to optimize income from limited quotas under strict regulation of catch and by-catch, the reliability of a CPUE index of abundance is very questionable for many important stocks. In addition, such indices have been shown to be misleading with respect to changes in demersal stock abundance, often caused by changes in distribution and migration patterns which have been observed to takes place in stressed fish populations (Ulltang, 1977; Rose et al., 1994). 


\section{Standardization and Assumptions in Surveys}

Standard surveys are all built on simple equations where an observation parameter $(d)$ is assumed to be directly related to true the density of fish $(D)$.

$$
d=k D
$$

where $k$ is an adjustment or efficiency factor with different meanings depending on the survey method. The extent of standardization varies between surveys but normally include restrictions on vessel type and size, sampling gear, time period for the survey, procedures for launching and retrieving the sampling gear, sample treatment, and data analysis. Some of the basic assumptions are:

- efficiency of the sampling gear is constant within the frames set by the standardization,

- all or a constant proportion of the population is available to the sampling gear over time and between surveys,

- a fixed survey period removes seasonal variability, and

- when a standardization regime is followed temporal integrity of abundance estimates is maintained.

When data are utilized in multi-species or ecosystem models, more assumptions have to be added, for example related to differences in catchability between size groups and species.

Trawl Surveys. A trawl survey is the most wide spread method for the assessment of a demersal fish stock. In this method $k$ (Equation 1) is related to the survey trawl's catching efficiency $(q)$. For swept area estimates, Equation 1 can be written:

$$
c=q D a
$$

where $c$ is the trawl catch, and $a$ is the area swept by the survey trawl, and $q$ is the catchability coefficient. If fish are also in the water column above the catching height of the trawl (Fig. 1), it is convenient to split the efficiency between an availability $\left(q_{a}\right)$ and an efficiency element $\left(q_{e}\right)$ (God $\left.\varnothing, 1994\right)$.

$$
q=q_{a} \cdot q_{e}
$$

Due to lack of exact information, $a$ (in eq. 2) is often assumed to be the area swept by the trawl's wings or doors during a standard tow, and $q$ is given the value 1 or a more or less arbitrary value (Gunderson, 1993). Due to the importance of this method for stock assessment, the assumptions underlying trawl surveys have been thoroughly studied in recent years. Studies have concentrated on issues relating to the trawl itself (sampling trawl geometry and performance, and trawl catching efficiency) and the response of fish to the trawl. In the following some documented divergences from the basic assumptions of trawl surveys will be presented.

The trawl. During the first 20 to 30 years of standardized trawl surveys the possibilities for monitoring the geometry and performance of trawls were very limited. Indirect measures of, for example warp angles, gave indications of the spread of the doors. But to a great extent the integrity of survey results remained dependent on the assumption of survey consistency. Studies of trawl performance and geometry by modern acoustic trawl instrumentation have demonstrated some fundamental disagreements with the basic assumptions. Trawl geometry measures, like wing spread and trawl height, are never constant (Godø and Engås, 1989; Rose and Walters, 1990; Koeller, 1991). Most commonly, the area swept by the trawl increased with depth and hence density estimates for deep water were systematically overestimated compared with those in shallow water. Also, obvious lack of stability in trawl performance, such as unstable bottom contact and error in measured tow duration, was discovered when gear performance was systematically monitored (Engås and Godø, 1986; Walsh et al., 1993). Such instability is normally caused by uneven bottom conditions or by the construction or rigging of the gear itself and may contribute substantially to the imprecision of the survey indices. Monitoring of trawl geometry has become standard in 


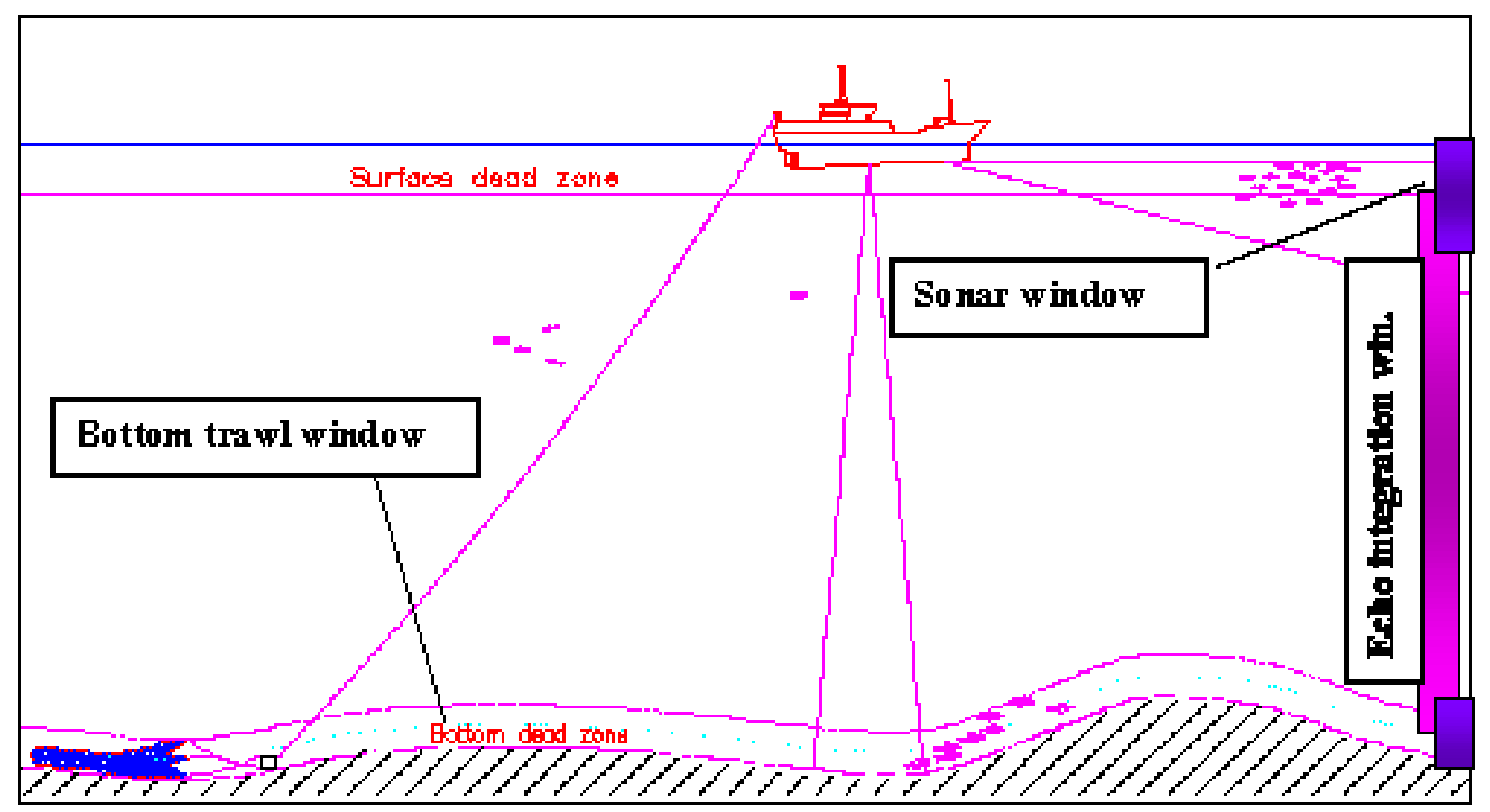

Fig. 1. Observation windows of a bottom trawl, a hull mounted acoustic transducer and sonar. Difference in vertical distribution of fish affect performance of the different methods.

many surveys, but there is still reluctance to change equipment or procedures to reduce its effects (Walsh et al., 1993), although there are examples of the implementation of new techniques (Engås and Ona, MS 1991; MS 1993; Mehl and Nakken, 1996). The key question is to what extent a change in procedures invalidate a survey time series. However, the documented fact is very clear; the original standard procedures created systematic errors in standard survey indices due to for example depth dependent trawl geometry, and random errors due to for example variable trawl performance.

The catching efficiency relates the catch to the actual fish density in the area swept by a trawl tow (Equation 2). If this relationship is a function of size or species, a selection process take place. Trawls are very selective sampling gears. Size and species selection may occur at all stages after the fish appear within the zone influenced by the trawl; for examples at the doors, sweeps, trawl opening and mesh selection within the trawl. Often, commercial fish or shrimp trawls have been chosen for a survey. Mesh selection has been studied for a long time and, normally, its effect has been limited in survey trawls by introducing a new small meshed cod end or a small meshed liner in the old cod end. Due to the unknown effects of selection, it is normally assumed that efficiency is independent of species and size, or at least that efficiency remains constant by species and age. Selectivity studies of survey trawls have revealed very strong size and species dependent differences and, in particular, low efficiency for small fish. The loss of small fish has been shown to occur both by escapement under the trawl (Engås and Godø, 1989a; Dahm and Weinbeck, MS 1992; Walsh, 1992a; Godø and Walsh, 1992; Erich, MS 1987) (Fig. 2), and in the sweeping zone of the trawl (Engås and Godø, 1989b). When growth rates change over time, inconsistency in time series indices of abundance by age will arise (Godø and Sunnanå, 1992). Such species and size differences will, in many cases, create great uncertainty in eco-system models which depend on survey results.

The fish (natural fish behaviour). The natural behaviour of fish may affect trawl surveys in many ways. Few of these effects have been studied and none adequately for a quantitative assessment. For trawl 


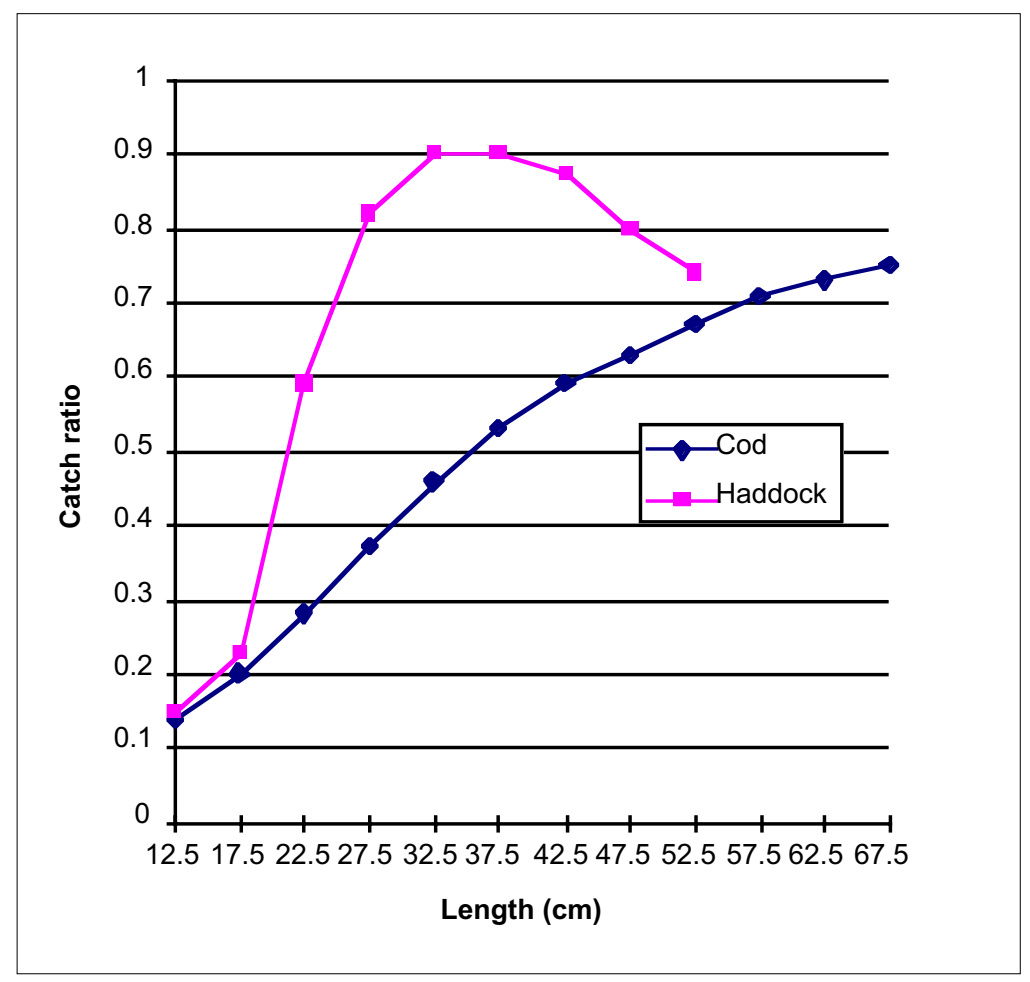

Fig. 2. Measured efficiency difference of old $v s$ new Norwegian sampling trawls with respect to size dependent escapement of fish under the trawl $($ ratio $=$ old $/$ new $)$.

surveys, it is normally assumed that fish behaviour varies according to certain patterns, and that a standardized survey is not affected or consistently affected from year to year. Two factors, which appear to be of great importance for survey abundance time series, are variation in availability $\left(q_{a}\right)$ (Fig. 1) and changes in organization structure.

For northern gadoids, changes in availability potentially may strongly bias survey results (God $\varnothing$ and Wespestad, 1993; Beamish, 1966). In some years, for example cod might be concentrated at the bottom and available for bottom trawling, while in other years much of the stock might be distributed pelagically well above the headline height of the trawl (Godø and Wespestad, 1993; Karp and Walters, 1994). There are additional complexities in how to treat data from surveys due to the uncertainty related to the effective catching height of the trawl (Aglen, 1996). Substantial and varying avoidance of pelagically distributed gadoids to trawling noise has been observed (Ona and Godø, 1990; Nunnallee, 1991; Godø and Totland, MS 1996). The problems connected to unavailability may also affect "true" demersal species like flatfish, as they have been found to distribute high up in water column during certain periods (Metcalfe et al., MS 1994).

It is well known that commercial bottom trawl catches are highly variable and often have a strong diurnal component (see e.g. Parrish et al., 1964; Walsh, 1991; Engås and Soldal, 1992; Michalsen et al., 1996). Repeated tows at same location demonstrate this, and Godø et al. (1998) suggest, for example that 5-7 trawl stations are needed to stabilize estimates of density and other stock parameters for gadoids. Seasonal changes in CPUE may be independent of stock abundance as it, for example, appears to be for the commercial CPUE of cod in the Barents Sea. CPUE seems to change very fast over time for unknown reasons (Fig. 3). Periods of unexpected low catchability could be caused by unavailability. Acoustic recordings of fish in the pelagic zone would then be expected, while anecdotal information from the fishermen indicates that under such circumstances recordings of fish are scarce. If such changes in catch rates 


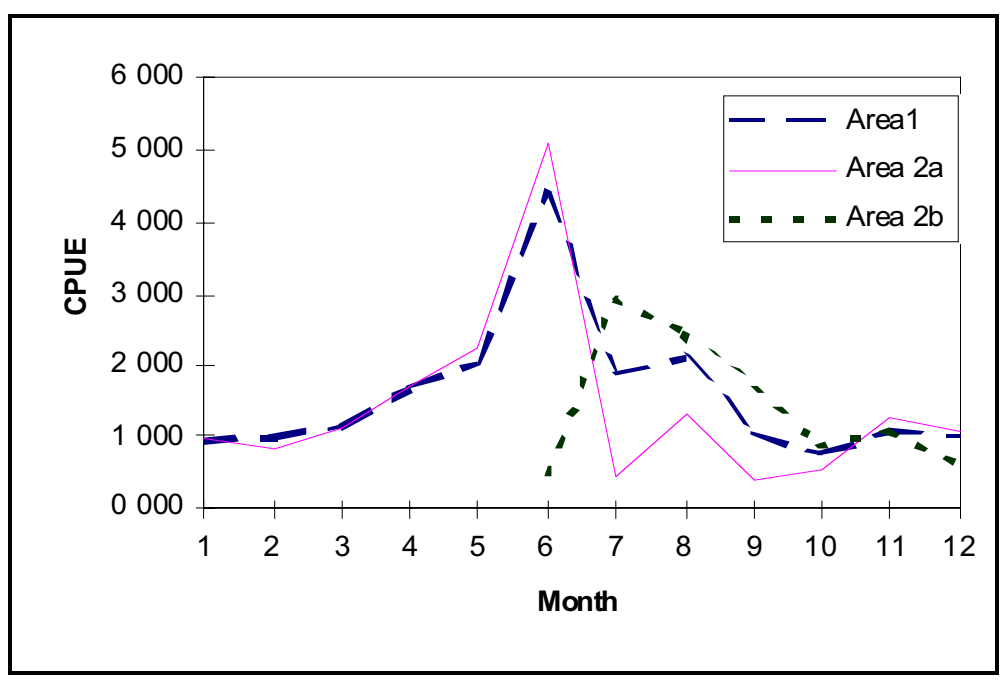

Fig. 3. Change in CPUE of cod by month as observed in the Norwegian bottom trawl fleet in, 1986 by Subarea.

occur independent of variation in stock level, they might also substantially affect survey indices. It has been speculated that catchability $(q)$ is affected by the internal organization, i.e. whether the fish are distributed as single individuals or in patches or schools. Schools react collectively and organize based on group stimuli while individuals have a more random reaction pattern and a higher escape rate during the catching process (Godø, 1994; Aglen et al., MS 1997). Similarly, comparison of catches from static gears (longline and gillnets) and trawls have shown that trawls might have high catches when static gears are unprofitable and vice versa. It is quite clear that variation in fish behaviour may cause unforeseen variation in survey CPUE in contrast to the basic assumptions. Quantification of its effects on survey results and even understanding the dynamics of the problem is presently very limited.

Acoustic. The estimates of abundance obtained from the acoustic method rely on the recorded reflected energy from fish as a measure of biomass density (acoustic back scattering cross section). The basic acoustic relationship is usually rewrites Equation 1 as:

$$
S_{A}=\rho \sigma
$$

where $S_{A}$ is the acoustic index (the average back scattering cross section per naut. mile ${ }^{2}$ ), $\rho$ is the area density of fish, and $\sigma$ is the conversion factor (average backscattering cross section per fish). Performance is poor in the near bottom zone and close to surface (Aglen, 1994; Ona and Mitson, 1996, Fig. 1), and thus the conversion factor for a acoustic survey depends on an availability and an efficiency factor:

$$
S_{A}=\rho \cdot \propto \sigma
$$

where $\propto$ measures the proportion of fish available to the acoustic beam.

Studies of the acoustic methodology have shown disagreement with the underlying assumptions concerning instrument performance, particularly in relation to fish distribution, behaviour and biological characteristics of the fish.

Instrument performance. For acoustic surveys, $\sigma$ relates the acoustic signals to fish density and is correlated with the size composition of fish obtained from trawling. Instrumentation in acoustic surveys thus includes the electronic instruments as well as the gear used for sampling the recorded fish. 
In acoustic surveys, stable performance is assured through standard calibration (Foote et al., 1987). However, reduced performance can be caused by bad weather conditions mixing air bubbles into the surface water. A weak layer of bubbles might seriously affect results (Ona, 1994). The increasing beam volume with depth reduces the actual reflected energy from small targets, and the effective sampling volume for varying fish sizes might changewhen noise thresholding is applied.

Normally a trawl or another selective gear is used to sample the acoustic recordings. Thus, the reliability of the estimated abundance by size and species depends on the representativity of the samples given by the trawl sampling. Splitting of the acoustic recordings by species is normally done either from characteristics in the appearance of the recordings or based on the fish samples. Misinterpretation may occur, for example wrong splitting by species when visual appearances are similar (MacLennan and Simmonds, 1991). Therefore, the reliability of estimates from acoustic methods depends on the same factors as discussed under bottom trawl surveys. The problems connected to pelagic sampling, which is the most common sampling method in acoustic surveys, are in principle the same as for bottom trawling although the factors may vary in importance (see e.g. Aglen, 1994; Simmonds et al., 1992; Foote and Stefansson, 1993). In mixed pelagic stocks there is a great deal of complexity related to obtaining correct representation by species (Masse and Retiere, 1995). Stock organization (i.e. schooling or non-schooling) season and light condition are factors of great importance for catchability. In addition are the assumptions involved in collection and treatment of the acoustic data (Simmonds et al., 1992)

The reflected energy depends on the performance of the acoustic instruments and the acoustic properties of the recorded fish. The acoustic properties of fish are assumed to follow standard size dependent relationships. Recent studies have shown and quantified the dependency of reflected acoustic energy on biological characteristics (gonad development, fat content, stomach fullness) and depth. Some of these factors will thus vary seasonally (gonad development and fat content) while others will vary diurnally caused by light influenced vertical migration (Ona, 1990; Huse and Ona, 1996).

Fish behaviour. As for the bottom trawl survey, the performance of the acoustic survey can be impaired by the inability of acoustics to cover the whole vertical distribution of fish. The $\propto$ factor relates the ability of the instruments to record fish under different distribution and/or avoidance patterns. Pelagic fish may "hide" in the near surface layer (Misund, 1994) and demersal and semi-demersal fish in the bottom zone (Ona and Mitson, 1996; God $\varnothing$ and Wespestad, 1993). If a varying fraction of fish distribute in these zones over time, it might seriously affect the consistency of survey results (Fig. 1, Aglen, 1994). If fish react to an approaching vessel with a horizontal (Ona and Toresen, 1988) or vertical (Ona and Godø, 1990) avoidance movement a "dilution" of the real fish density in the observation window has been measured. When avoidance reaction is away from the survey vessel as in Fig. 4, the fish tilt angle will change. The backscattering properties of the fish are seriously affected by any change in tilt (see e.g. Aglen, 1994 for overview).

Fixed Gear Surveys. In fixed gear surveys it is assumed that a relationship between the true density and the catch of a standard effort unit exists. That is:

$$
c=D k
$$

For fixed gears, a contact and eventual catch depends on the level of fish activity. For baited gears, the current conditions and setting strategy in relation to the current are also decisive factors for the efficiency of the gear (Engås and Løkeborg, 1994; Engås and Jørgensen, MS 1997). As suggested above, the contrasting differences in efficiency of static and active gears emphasize the importance of variation in natural behaviour on abundance indices generated by static gears. As the efficiency of static gears is so greatly dependent on variation in the behaviour of the fish and their environment, it is reasonable to believe that the effects of varying behaviour are more pronounced for static gear surveys. 


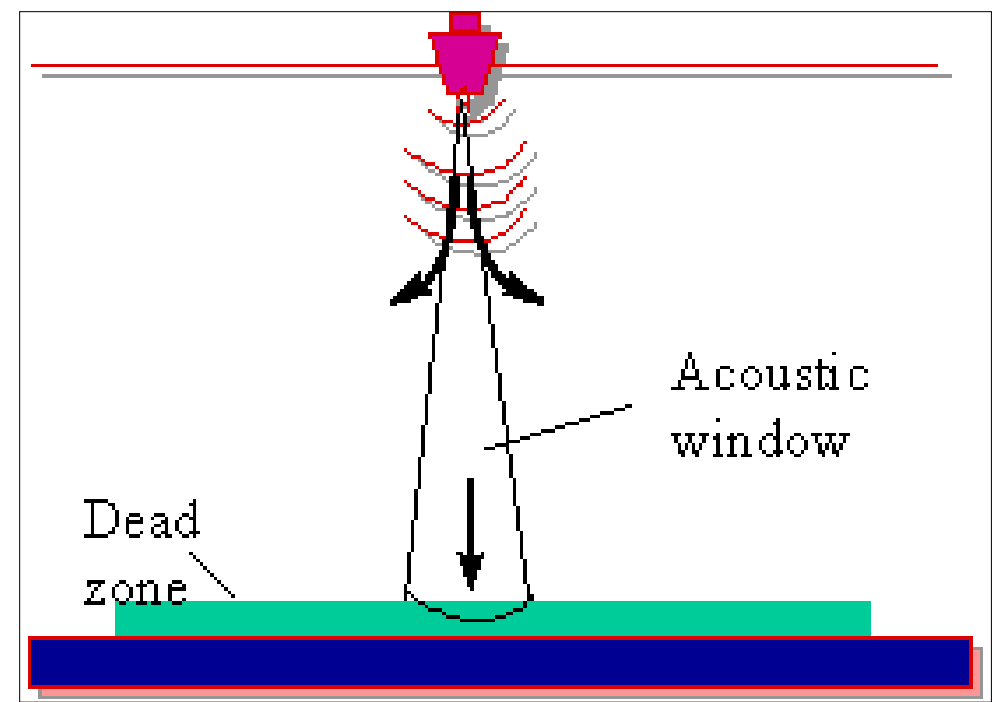

Fig. 4. Horizontal and vertical avoidance movements (arrows) of fish out of the acoustic observation volume.

\section{Technology and Future Improvements of Stock Assessment}

Better stock assessment can be obtained through new or improved observational tools and methods, and/or by increasing the basic biological understanding and knowledge. Improved or new observational tools and methods will generate more reliable data - hereafter called monitoring application. Errors produced due to rough assumptions connected to survey methodologies can be eliminated or minimized through changes in gear or by application of models fuelled by new and improved basic knowledge. When technology is used in this way it is called fundament application. Finally, calibration applies technology to compare gears (e.g. two trawls) or to quantify an effect (e.g. size selection in trawl opening). In this section some observational techniques not used or under-utilized in standard survey methodology will be presented. Their potential usefulness for the future development of new and/or improved field observational methods for estimating stock abundance will be discussed.

\section{Physical Measurements}

Physical measurements cover a variety of variables of which I will give an overview of those important to trawl geometry and performance as they relate to the three categories mentioned in the last section.

Trawl Geometry. Acoustic trawl instrumentation has been available for more than a decade and is now used in many surveys (Engås and Godø, 1986, Walsh et al., 1993, Engås, 1994). The most common monitoring application is for measuring the door/wing spread and trawl height. The application of such data has varied. The passive user adjusts the catch for the deviance of the measured swept area from the assumed standard. The active user interactively uses the measurements to adjust the trawl geometry during the tow. Presently, this can be done by paying or heaving warp (Koeller, 1991). Technically this can be accomplished by an automatic interactive feedback loop between the trawl instrumentation and the winches (e.g. Scantrol, Bergen, Norway). The drawback of this approach is that door performance will be affected if the depth - warp scope ratio varies substantially (Engås, 1994). Alternatively, the spreading force of the doors can be interactively adjusted through either opening and closing windows in the doors or changing the attack point of the warp bracket on the doors. An acoustic link used in trawl instrumentation has been developed which can control electrically powered opening-closing devices on doors (Scanmar, Horten, Norway). Another monitoring approach, which is used in a Norwegian bottom trawl survey, is to use over dimensioned doors and then lock the spread by attaching a constraint rope on the warp (Engås and Ona, MS 1991; MS 1993). The length of this rope and its position on the warp can be adjusted to meet the 
'ideal' spread of the doors. An acoustic sensor is attached to the rope to monitor the height of the rope above bottom. Thus, the door spread and the warp angle can be kept constant under all conditions (Fig. 5).

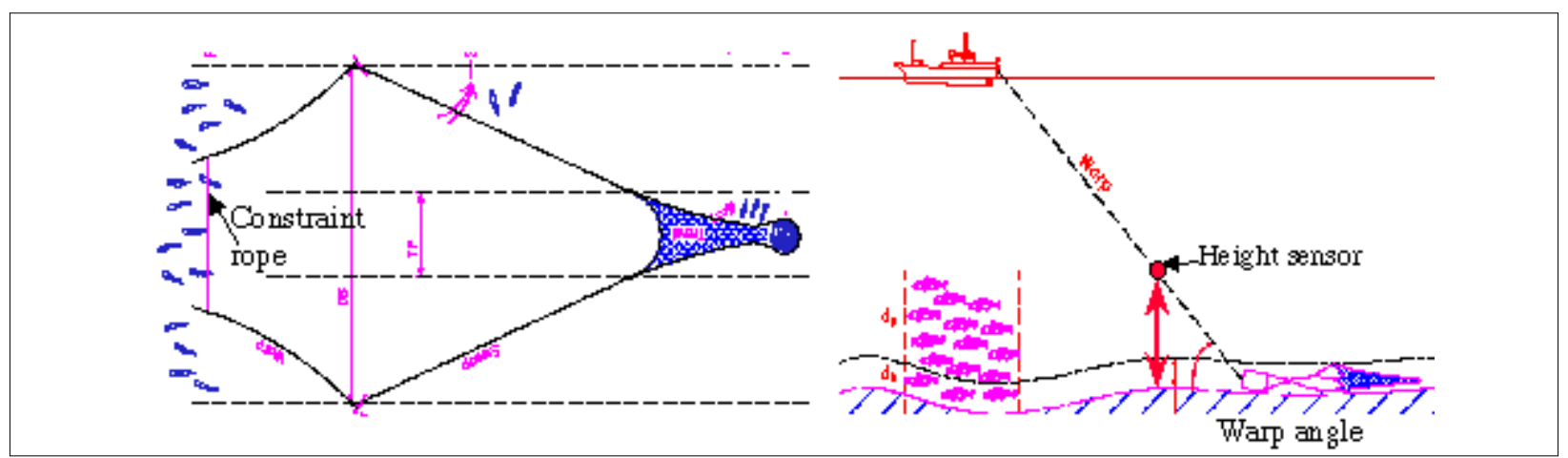

Fig. 5. The use of constraint rope (left) with acoustic instrumentation (right) to maintain constant the swept area and performance of a bottom sampling trawl.

Trawl Performance. Existing trawl instrumentation is used to evaluate and monitor trawl performance. The height and spread sensors give good clues on door stability and the stability of bottom contact by the trawl (Engås, 1994). Bottom contact is a crucial factor for the validity of a standard trawl survey haul, but the information can be difficult to evaluate due to noise in the data caused by data transmission (Walsh et al., 1993) and can not be properly monitored with available sensors. A sensor or a series of sensors attached to the bottom trawl's ground gear which continuously records the on or off bottom condition is necessary to properly evaluate trawl performance. Demersal fish in front of the trawl search for escape paths along the ground gear and thus periods of only a few seconds with no bottom contact may severely affect the catch. A proper on and off bottom sensor system will be important for future evaluation of the effective area swept by a trawl haul. Development has started and a product will probably be on the market within few years. Equipment for controlling trawl performance should be developed for monitoring application, i.e. to be used on all tows.

Tow Duration - Swept Area - Swept Volume. The area swept by the trawl is determined by the door spread and the distance over which the trawl has been towed. The door spread is or should be properly monitored and kept close to target spread. Presently, the target tow distance is obtained by towing a fixed time at a measured or assumed speed, or, alternatively, by heaving when the satellite position system show that the target distance is covered. This gives the most precise speed with respect to the bottom, which at least should be a proper measure of speed for bottom dwelling individuals. Free swimming fish might be more connected to the water masses than to the bottom substrate. Thus, the trawl speed through the water might be more relevant than speed over the ground. Speed sensors that record water flow are available and can be attached to the trawl and used to determine the speed through water. Also, such speed sensors split the water movements in along track and transverse track components. The transverse component can be used to improve trawl performance, i.e. side current is eliminated by regulation of scope or tow direction.

By means of the measures of speed obtained from GPS (Global Positioning Systems) and underwater speed sensors, the trawl movement relative to the water current can be derived. Fish behaviour is known to be strongly affected by current (see e.g. Arnold, 1981). Fish often orient against the current to maintain position when influenced by a strong current. The trawls direction of attack relative to the swimming direction (or current direction) might be of greatest importance for the catching efficiency of some species. Therefore, standardization of procedures should involve a standard tow direction related to the current direction. If reliable current models exist for the survey area (see e.g. Gjevik et al., 1994) these can be used to predetermine tow direction. Also, instruments for measuring the current in situ are available 
(see next section about Acoustic Doppler Current Profiler (ADCP)) and can be used to determine the current on site before setting the trawl. The relation of catching efficiency to tow and current directions needs to be determined as a foundation for improved survey procedures.

Towed distance determines, together with the effective sweeping width, the area swept by the trawl, and any error in measuring this area will directly affect the estimated density. The uncertainties in the measures of trawl spread and trawl bottom contact have been discussed above. In particular, the uncertainty caused by varying bottom contact needs more attention. If varying bottom contact is a problem, a simple adjustment of the effective distance towed might be an underestimate of its effect. Fish are known to swim in front of the trawl before falling back into the codend. Consequently, fish from a much larger area than that represented by the disrupted bottom contact might be lost.

Auxiliary (Environmental) Variables. Temperature is usually measured during standard surveys. Temperature affects the distribution pattern of fish as well as catchability. In laboratory conditions swimming performance is known to be dependent on temperature (Wardle, 1993) and in the field catchability is probably a function of temperature. Individual Northeast Arctic cod are known to experience a temperature span of about $5-8^{\circ} \mathrm{C}$ and within day changes of $5^{\circ} \mathrm{C}$ have been observed (God $\varnothing$ and Michalsen, MS 1997). It is assumed that these temperature effects are stable from survey to survey. However, the distributional changes experienced by, for example cod in the Barents Sea in the late-1980s and off Newfoundland-Labrador in the 1990s with accompanying dramatic declines in stock abundance are examples in which temperature could have contributed both to distributional changes and to survey catchability.

Current is important for odour transport in fixed gear surveys, affects the vertical distribution during acoustic and bottom trawl surveys, and the catchability of bottom trawl surveys. Current can be monitored during surveys by means of an ADCP. These instruments are expensive and are seldom used directly or indirectly in surveys. New cheaper versions, with a more user friendly interface, are about to come to market (Gordon, 1997). Thus, setting strategies of sampling gears (static as well as trawls) can be decided based on ADCP readings of the current. Continuous logging of current may also become a useful tool for evaluating vertical distribution and availability in bottom trawl and acoustic surveys (Michalsen et al., 1996).

Bottom type can be monitored by acoustic instrumentation (see e.g. Magorrian et al., 1995). Bottom characteristics affect the distribution of true demersal fish. Thus, monitoring of bottom type acoustically can improve the stratification of bottom trawl and fixed gear surveys.

Light is known to be a very important environmental clue for determining the catching efficiency of trawls (Glass and Wardle, 1989; Wardle, 1993). Light condition during a trawl haul is presently estimated indirectly from the time of day, latitude, cloud coverage, and water turbidity. Only direct observation of light at trawling depth will give reliable information on the light conditions during trawling.

Satellite monitoring of environmental conditions (e.g. temperature, production and ice cover) is feasible. For survey estimation of fish abundance, such data can be valuable in determining survey and sampling strategies. These measures are constantly improved and if relationships between them and fish distribution and behaviour are established, they can become an important tool in survey strategy and possibly also in abundance calculations. For some surveys, development of survey efficiency models to determine the most favourable coverage based on the information available before and during the survey may help when survey resources are limited.

Environmental variables have been used for a long time in, for example recruitment, growth and ecosystem models. Such factors could also be applied to biological data from surveys. Particularly light and temperature, but also current might become important input variables for future catchability models. The basic knowledge needed for the development and implementation of such models is presently insufficient, and laboratory and/or fieldwork for studying fish reaction patterns to trawls under different environmental conditions is strongly needed (fundament application). 


\section{Observations of Fish Density and Behaviour During Survey and Sampling}

With improved and new underwater observation techniques there is a great potential for improving the sampling techniques for estimating density and species composition during field studies and routine surveys. In addition, new techniques can be used to improve understanding and quantitatively assess the effect behaviour has on survey gear efficiency. Further, as improved methodology replaces old standards, reliable calibration techniques are needed. As shown above, the present standard assessment paradigm is built on (assumed) fixed relationships. Improved knowledge and understanding of, for example species and size dependent behaviourial dynamics, both natural and gear induced, emphasizes the limitations of such assumptions. Future challenges will be to quantify and implement this type of information into a new "standard" methodology.

Direct Observation Techniques. These techniques include direct visual observation, photo observation, video and laser techniques. Since the late-1950s the Russians have developed a towed submarine to observe directly fish density by size and species (Zaferman, 1979). The observer was "calibrated" using fish of known size and species. The method has been used for the calibration of survey trawl efficiency. The uncertainty caused by operating limitations due to light and depth conditions and potential interaction between an approaching submarine and the fish reduces the method's applicability. In warmer water and at shallow depths, divers have been used to observe density and fish behaviour. Diving and submarine technology will certainly develop and improve. However, its application in quantitative biology is limited due to the restrictions mentioned above.

Photo and video techniques have some of the same limitation as mentioned for direct visual observation. The applicability of these techniques is however, much wider. Cameras get smaller and more light sensitive and can be used to directly observe fish behaviour and the efficiency of fixed gear as well as to estimate escapement by size and species (Fig. 6). Weinberg and Munro (MS 1997) have done systematic video studies in an attempt to arrive at efficiency measures of a sampling trawl by species and size. Also various arrangements with video cameras operated from towed vehicles are used for the same purpose (Main and Sangster, 1981). More extensive use of digital cameras and automatic software to analyze videos may substantially improve this method for calibration purposes. Again the limitations of such studies are the same as for visual studies. Light and depth will, in many cases, set limits to the representativity of the observational setting as compared with the survey situation. Systematic flash photos taken during a trawl haul might give valuable information on behaviourial day-night differences (Walsh and Hickey, 1993), but again there is the uncertainty of the effect that artificial light has on behaviour.

A problem with the above techniques is the estimation of size because the distance to the object is not known. Camera arrangements for taking stereo photos might improve the three dimensional perception of the observed volume and hence size determination. Also, combining information from other tools, for example analysis of simultaneous video and sonar picture might in the future improve distance and size determination.

The use of lasers in underwater fisheries studies has until now been very limited. In the US lasers have been tried for crabs, but the results were not satisfactory with respect to reliability, performance and cost (Somerton, Alaska Fisheries Science Center, pers. comm.). A Russian development that uses lasers to study underwater fish behaviour has been reported (Zaferman, 1997). The laser is reported to use light which does not disturb the fish. The observation distance is asserted to be approximately double that for video cameras. Lasers also provide improved size determination since they also can be used to measure the distance to an object.

The use of direct observation techniques has until now been mostly for fundamental application. Our basic insights on fish behaviour dynamics come, to a great extent, from these techniques. The limitations caused by light and depth conditions as well as effects the equipment has on target species restricts the general applicability of these results. Monitoring application of camera or video techniques to assess density of sessile or semi-sessile organisms are presently developing for several species. Further develop- 


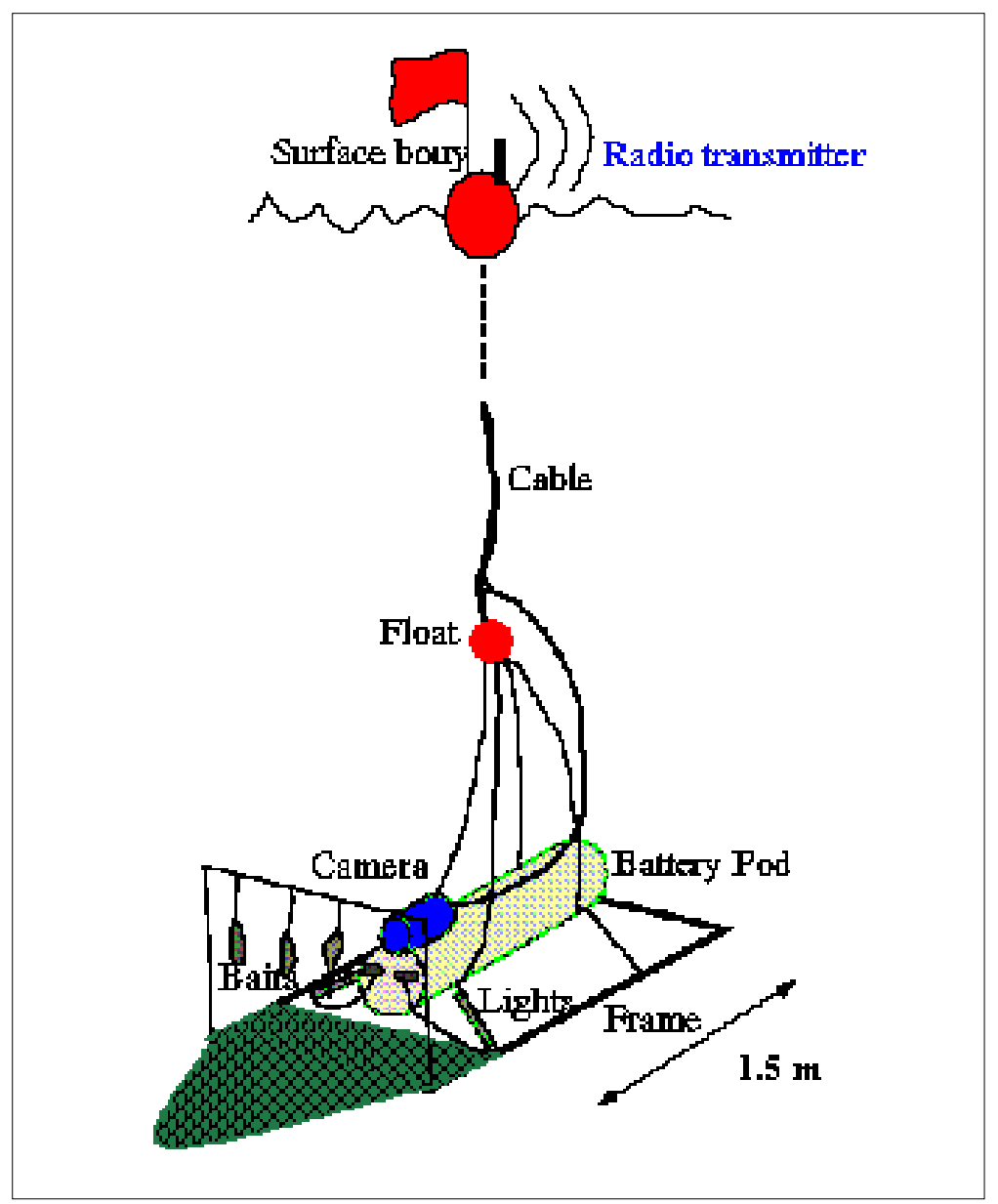

Fig. 6. A video observation arrangement for monitoring fish behaviour in the catching process of longlines (Godø et al., 1997).

ment of laser techniques might potentially improve their use in calibration and, perhaps, for monitoring applications not only of sedentary organisms but also of fish.

Tagging Techniques. Tagging is widely applied in fisheries studies today. Traditional external tags are used for migration studies, various internal tags and micro wire tags are used for assessment purposes, and acoustic transponder tags have wide applications in fish behaviour studies (Arnold et al., 1995). No comments will be made here on these methods but rather concentrate on new developments in electronic tags. The miniaturization of electronics has opened the way for new tagging applications. Tags, which store information on environmental, physiological and chemical processes, are attached to the fish and the recorded data are downloaded after recovery (Anon., MS 1997). Thus, detailed information on fish natural behaviour or physiological rhythm in relation to its environment can be studied over long periods. For species that occur close to surface, a light a sensor can be used to determine geographical position from information on sunrise and sunset (Gunn et al., MS 1994). Also, when the fish have a certain behaviour in relation to current, fish movements can be modeled quite well (Metcalfe et al., 1993; MS 1994). For species which are assessed routinely by surveys, it is crucial to know their vertical behaviour pattern for evaluating the efficiency of different survey methods (see Fig. 1). For acoustic surveys, the tilt angle of the fish, which can be monitored by such tags, determines an individual's acoustic property. Figure 7 shows a cod being tagged with a data storage tag (DST) that records temperature, depth and tilt angle along with a plot of depth and temperature from a tagged fish at freedom for about one year. 


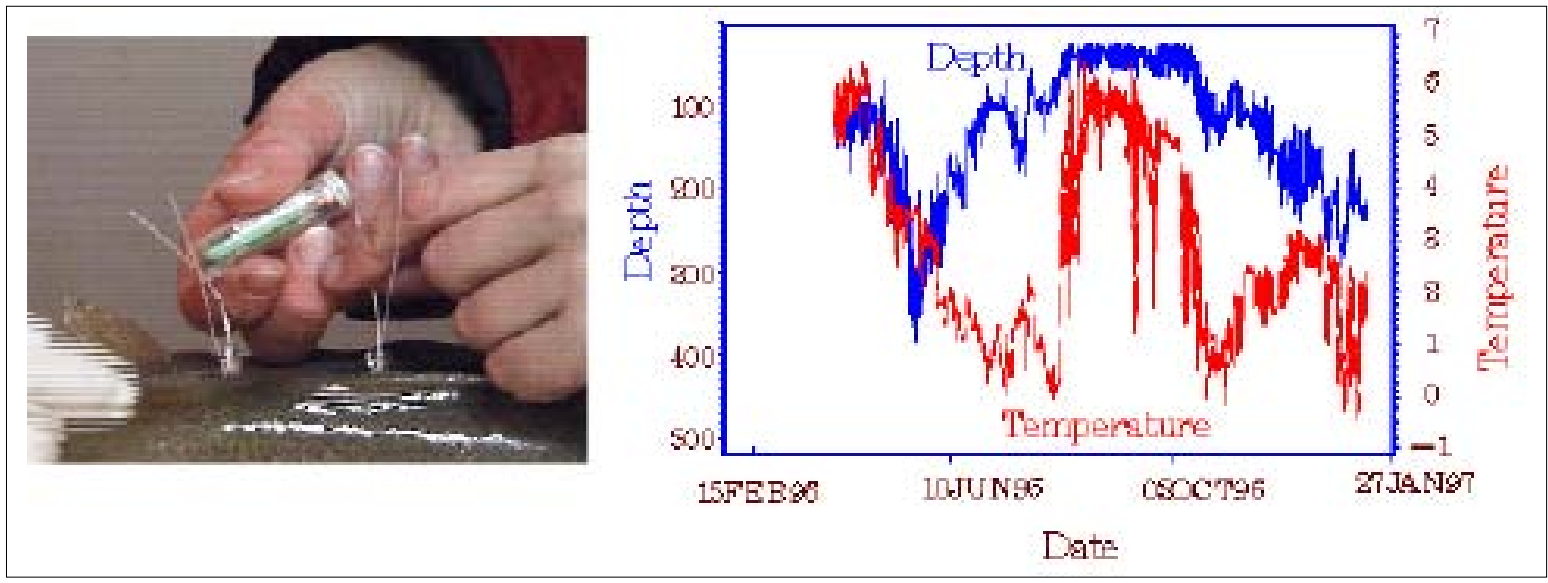

Fig. 7. Data storage tag being attached to a cod (left) and a temperature (blue) and depth (red) time series after about one year in sea.

Electronic tagging technology will certainly develop quickly in the coming years. Cheaper, smaller and with more memory, such tags will be able to gather more complex information about an individual fish. The development of new smaller and better sensors increases the possibility of a fundamental breakthrough in understanding fish migration and behaviour. Such fundamental applications may lead to improvements in survey strategies. Within a few years, different solutions for the positioning problem will probably be developed. Compass, tail-beat, heart frequency, and stomach fullness sensors are examples of new sensors, which are or will soon be connected to a DST tag. By means of information collected by electronic tags, new and quantitative information on feeding behaviour, activity patterns and migration behaviour will be achieved. Presently, uncertainties in survey assessments as well as in ecosystem models are caused by a lack of basic knowledge of conditions in the field.

Combined with the position of fish in relation to a trawling vessel, DST technology could improve our understanding of fish reaction patterns in the catching process as well as variation in catchability (calibration).

Mass tagging and scanning of commercial catches for recoveries is a method for direct assessment of fish stocks which presently is restricted to certain stocks due to limitations set by the tag scanning methods. With new developments in electronic tags, small response tags might be developed that will 'answer' when 'called' by an acoustic device installed on the fishing vessel or at landing site. Such monitoring applications might provide independent estimates of stock abundance for species such as cod that presently are practically impossible to assess with tag and recapture techniques. Development of new electronic tagging technology is expensive due to the low demand for the finished product. If mass tagging technology is to be stimulated, international agreements on sharing the development cost might be necessary.

Acoustic Techniques. Fisheries acoustics techniques for stock assessment and fish behaviour studies have developed tremendously during its roughly 30-year history (see e.g. MacLennan and Simmonds, 1991). It is still a young science with high potential for improving monitoring applications for fish stocks as well as fundament applications, for example through enhancing our knowledge on natural and disturbed fish behaviour. This continuously changing technology and hence the potential for instrumental variability demands proper calibration routines (Foote et al., 1987). Standardization of acoustic methodology means calibration routines and not a rigid and restrictive policy of not applying new technology. Agreements on calibration methods and standards improve the comparability of results obtained worldwide. 
Fisheries acoustics is the scientist's eye to a stock's underwater reality. Descriptions of the large variety of available instrumentation would fill a book. I will focus on giving a brief introduction to those of considerable interest for stock assessment. A rough overview of different acoustic systems and the platforms to which they are or may be coupled, are given in Table 1 and in Fig. 8 along with existing and potential applications. The choice of acoustic system and platform must fit the task to be accomplished.

Abundance and density. The goal of an assessment survey is to estimate stock abundance. The quality of such estimates is, however, dependent on many factors that can be classified into the four categories given in Table 1. Estimation of fish stock abundance by acoustic techniques will, in most cases, be based on hull mounted transducers. The data obtained from such transducers are often contaminated by noise caused by air bubbles in the surface layer generated by wind and waves (Ona, 1994). Even a weak layer of air bubbles may seriously affect results without being apparent in the acoustic recordings. Towed platforms have been used for a long time to get the transducer below the air bubbles. Platforms are now being developed which can be towed closer to the acoustic targets and thereby improve, for example near bottom registration of fish as well as deep water assessments of fish abundance not reachable by hull mounted systems (Dalen et al., 1995). Transducers mounted on retractable platforms (Ona and Traynor, MS 1990) are used on research vessels in the US and Norway with great success. Vessel operation can continue in rougher weather than before without any reduction in the quality of the data.

Reliable assessment of fish stocks which distribute outside the observation window of one method, for example surface distribution of herring above the depth of the hull mounted transducer (Fig. 1), depends on combining information from different sources. Due to difficulties in calibrating sonars compared to echosounders, sonar systems are less useful for direct assessment. However, recent approaches to measure the dimensions of pelagic fish schools and then estimate their abundance by hull mounted transducers according to standard acoustic methods, appears promising for several stocks (Misund et al., 1996).

TABLE 1. Acoustic methodology by platform type and application.

\begin{tabular}{|c|c|c|c|c|c|}
\hline Platform type system & $\begin{array}{c}\text { Abundance } \\
\text { density }\end{array}$ & $\begin{array}{c}\text { Acoustic } \\
\text { properties }\end{array}$ & $\begin{array}{c}\text { Natural } \\
\text { behaviour }\end{array}$ & $\begin{array}{c}\text { Affected } \\
\text { behaviour }\end{array}$ & Migration \\
\hline \multicolumn{6}{|l|}{ Vessel mounted systems } \\
\hline Traditional sounders & $x$ & $x$ & $x$ & & \\
\hline Sonar & $x$ & & & $x$ & $x$ \\
\hline ADCP & & & $x$ & & $x$ \\
\hline Drop sonde with transducer & & $x$ & & & \\
\hline \multicolumn{6}{|l|}{ Floating buoys } \\
\hline Traditional sounders & $x$ & $x$ & $x$ & & \\
\hline Broad band acoustics & & $x$ & $x$ & $x$ & $x$ \\
\hline \multicolumn{6}{|l|}{ Stationary systems } \\
\hline Traditional sounders & $\times$ & $x$ & & $x$ & $x$ \\
\hline Sonar & $x$ & & & $x$ & $x$ \\
\hline Broad band acoustics & & $x$ & & $x$ & $x$ \\
\hline ADCP & & & & & $x$ \\
\hline \multicolumn{6}{|l|}{ Towed vehicles (bodies) } \\
\hline Traditional sounders & $x$ & & & $x$ & \\
\hline Sonar & $x$ & & & $x$ & \\
\hline \multicolumn{6}{|l|}{ Automatic vehicles } \\
\hline Traditional sounders & $x$ & $x$ & $\times$ & $x$ & \\
\hline Sonar & $x$ & & $x$ & $x$ & \\
\hline \multicolumn{6}{|l|}{ Trawl systems } \\
\hline Traditional sounders & $x$ & & $x$ & $x$ & \\
\hline Sonar & & & $x$ & $x$ & \\
\hline
\end{tabular}




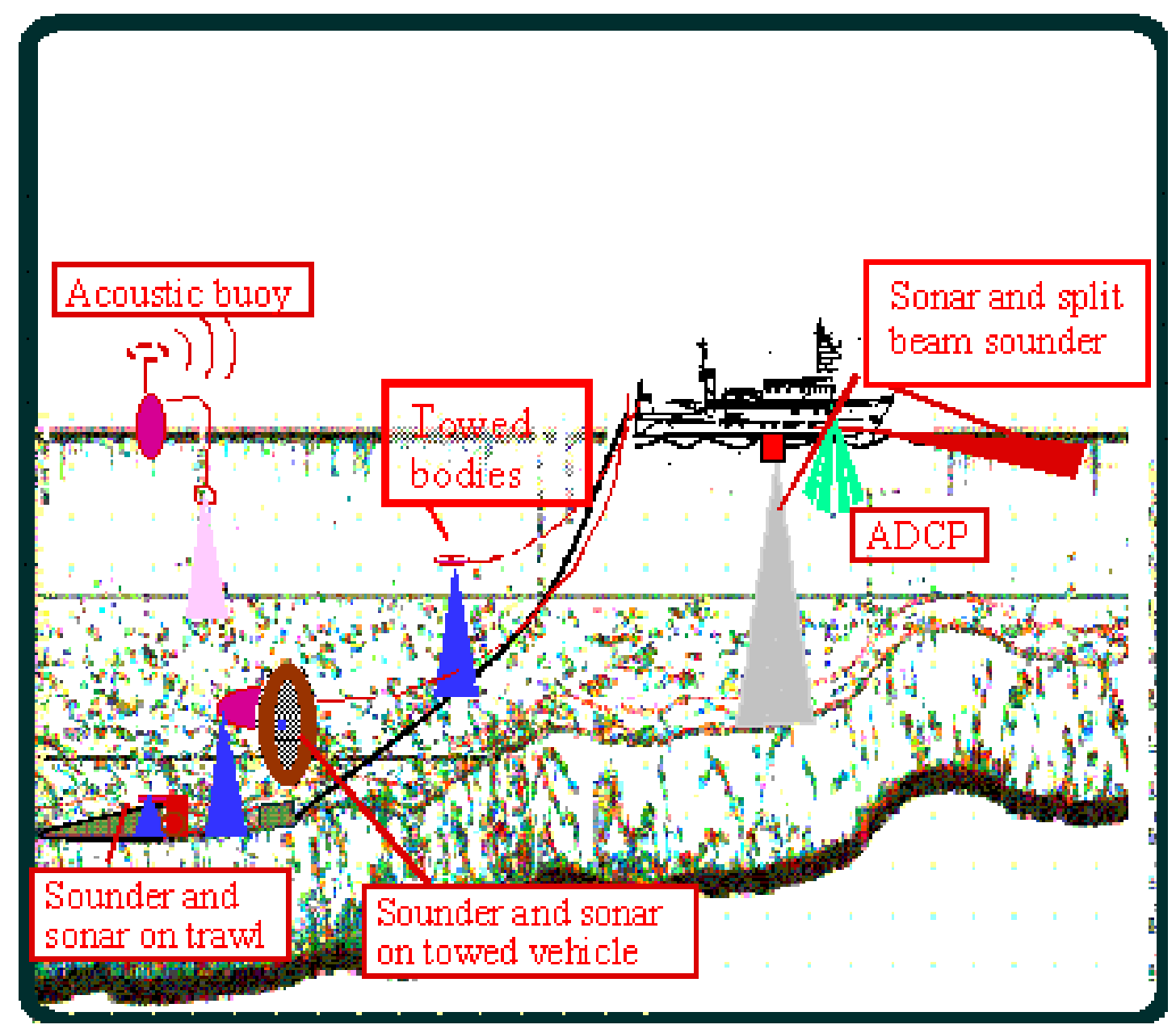

Fig. 8. Acoustic observation techniques attached to various platforms. The echogram shows recordings of gadoids partially available to the bottom trawl and the acoustic observation windows.

The combination of sounder and sonar technology is now being further improved, for example by development of a user interface, which will reduce the effects of operator bias (Dalen, Institute of Marine Research, Bergen, Norway, pers. comm.).

Data from several frequencies have been used to distinguish between fish and plankton. Reliable technology for quantifying differences in multiple-frequency displays needs to be developed and evaluated. Such development is now in progress (Korneliussen, Institute of Marine Research, Bergen, pers. comm.) with the purpose of improved species identification from mixed species recordings, and multiplefrequency methods may become part of standard survey procedures in the near future. The complexity of such information makes a visual comparison and evaluation very difficult. Utilization of such technology is dependent on integration by post-processing systems, e.g. BEI (Foote et al., 1991), which can quantify and present differences in a systematic manner.

In some situations, the effects and limitations caused by a noisy survey vessel with a hull mounted transducer seriously restricts our getting a representative picture of a stock. In particular, this is a problem when fish are distributed close to the surface and in very shallow areas, or if the species is very sensitive to vessel noise. Many solutions have been tried or proposed, for example using a paravan mounted transducer, a small boat with a transducer in the surface layer. New technology is now being developed that use long range automatic underwater vehicles (AUV). Some are low noise electrically powered crafts which can run with or without contact with the mother vessel. 'Hugin' is such a battery powered vehicle 


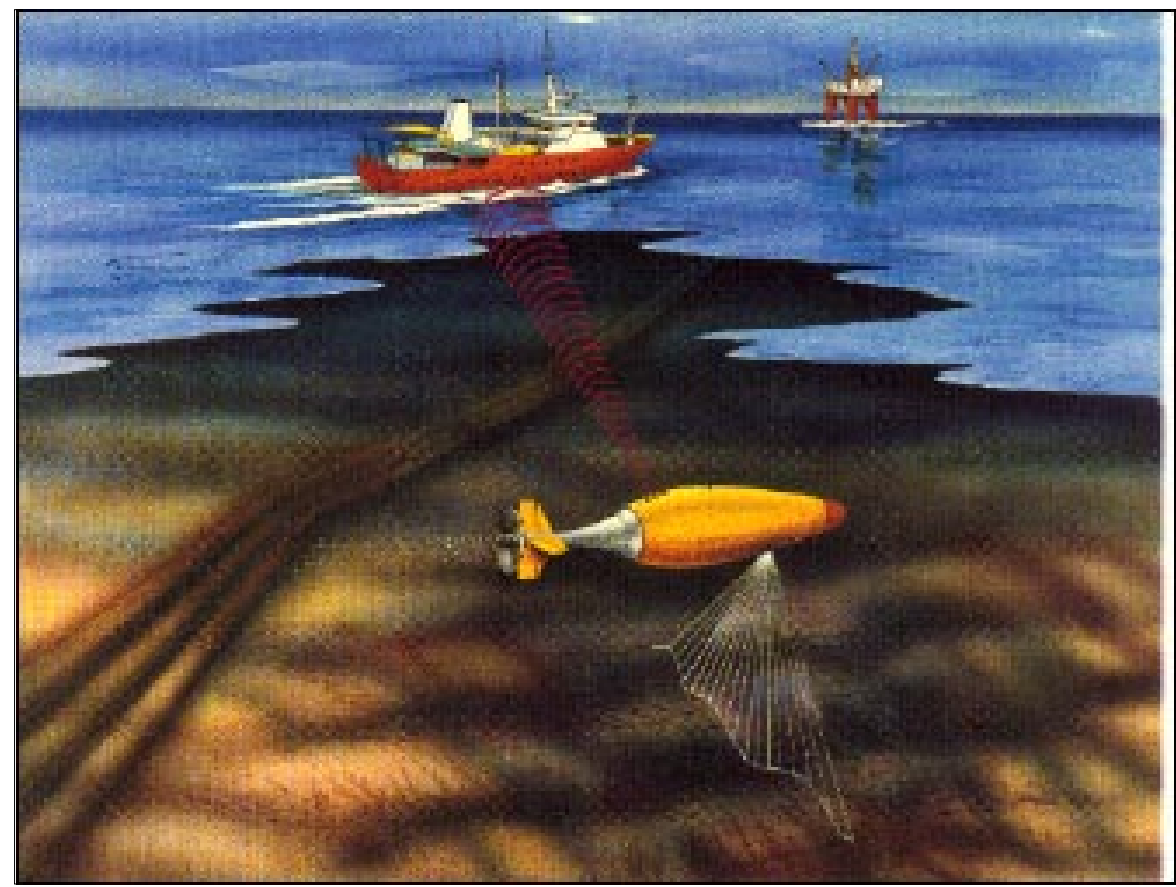

Fig. 9. 'Hugin' is a semi-automatic under-water vehicle able to perform a sonar survey of 36 hours. The data can be transferred via an acoustic link to the mother vessel and displayed as the survey proceeds.

(Fig. 9) that was developed for the oil industry (see Størkersen et al., 1996). It can run continuously for 36 hours and perform a sonar survey according to a pre-set cruise track. Sonar data are stored aboard but the data can be sent to the mother vessel via an acoustic link if within range. The vehicle monitors its environment and can avoid obstacles by changing depth or, go to the surface if a critical situation occurs. In the future vehicles of this type might be equipped with various acoustic equipment and become important research tools. A typical example would be to cover water too shallow for the main survey vessel. Constraints for survey assessment of major pelagic stocks in tropical areas are due to the shallowness of many habitats (Freon et al., 1993a). Also, small areas can be covered, for example to study immigration and emigration to a specific spawning ground.

Properties of the acoustic targets. A lot of work and techniques can and should be implemented to avoid unnecessary variability in acoustic estimates. Field and meso-cosmos studies show clearly that one can compensate for the substantial errors caused by varying behaviour and biological properties. Fat content and gonad development strongly affect the volume of the swimbladder and hence the back-scattering by the fish (Ona, 1990). These properties vary seasonally and can be measured (Zhao, 1996). Also, swim bladder volume is related to stomach contents (Ona, 1990), and the bladder expands and contracts with changing pressure due to diurnal vertical migration (see e.g. Huse and Ona, 1996).

Presently $\sigma$ (the back-scattering coefficient) is determined by a length dependent relationship where fish lengths normally are obtained from trawl catches. There are many problems connected to directly measuring the acoustic target strength of fish (Anon., MS 1995), however, development and improvements of observation techniques may minimize this source of variability. A major necessity is to come close enough to the target to reduce the probability of multiple echoes. This can be done by means of using a drop sonde (a pressure resistant transducer lowered towards the fish) or a deep towed body. To avoid vessel effects, an acoustic buoy or an AUV can be utilized (Table 1, Fig. 10). Instead of the traditional narrow band acoustics, broad band systems are now being developed which might reduce uncertainties connected to in situ target strength (TS) determination (Gordon, 1997). In situ TS measurements are necessary in order to make the acoustic method a totally independent method of stock assessment. 


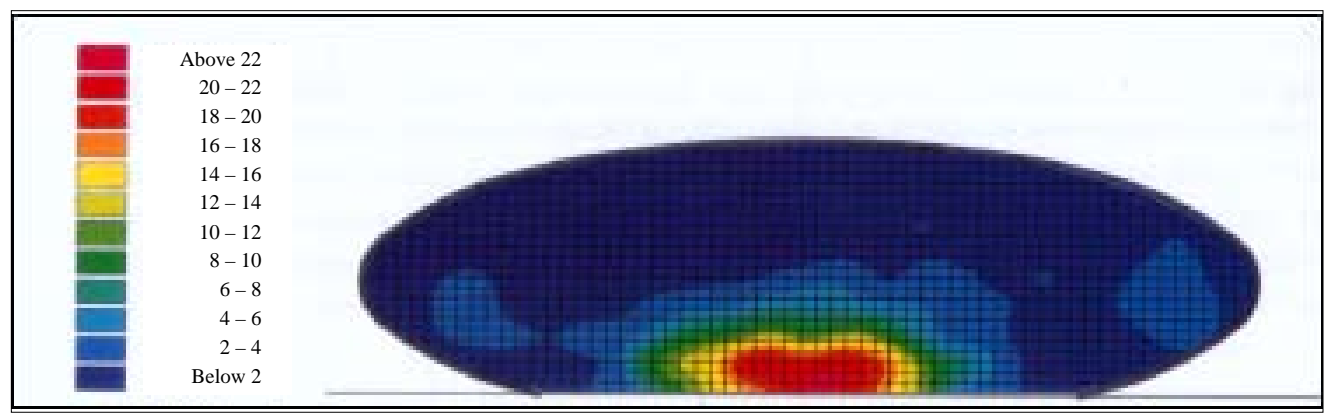

Fig. 10. Density distribution of fish within the trawl opening of a Norwegian bottom sampling trawl observed and positioned by a scanning sonar mounted on the headline of the trawl (from Ona, 1994).

Fish behaviour. Studies of fish behaviour in recent years have demonstrated the need for quantification and modelling behaviour to assess its effect on sampling reliability (Fernø and Olsen, 1994). Both natural and gear induced behaviour may significantly diverge from our basic assumptions (Godø, MS 1994). In addition, migrations during surveys may substantially bias a survey (MacLennan and Simmonds, 1991). There are now under development different types of floating buoys or stationary systems which can log and/or transfer data over long periods (Table 1, see also e.g. Godø and Totland, MS 1996). These systems may give valuable information on the variation in vertical distribution and migration. Furthermore, variation in acoustic properties over time can be studied.

The development of computer and acoustic technology reduces the size of equipment and its power demand, which will make possible the production of small units containing both the acoustic and the data logging instruments. These units will be placed in floating buoys, on the bottom or attached to sampling gears. Direct connection to the scientist can be established through acoustic, radio or satellite communication. This will become an important tool, both for studying natural and affected fish behaviour. In many cases escape behaviour during surveys will be modeled based on quantitative experiments (fundament applications). For other stocks variability in behaviour might demand the development of monitoring applications which will routinely measure the effects of escapement on the efficiency of the survey gear. Ideally, the research vessel should have an AUV to study fish distribution in front of the vessel and a controllable body behind to determine fish reaction patterns. Such set-ups might be possible for special studies but for routine surveys, equipment and procedures must be simple and straight forward.

The limitations for observing fish behaviour during the catching process were caused by, as discussed above; the need for light, the small observation volume and the difficulties in determining distances. Different types of scanning sonars have been used to study fish behaviour (Ona, 1994). They do not have the same limitations as cameras and, for example diurnal differences in distribution of fish in the trawl opening can be mapped (Fig. 10). Species identification is not possible, and full utilization could possibly be obtained by receiving samples from other methods (e.g. random flash photos).

ADCP is normally used to monitor currents in different layers based on particle reflections. Similarly, if a layer or a shoal of fish is recorded, its movement in relation to the surrounding water can be measured. Instrumentation and software are now under development to exploit this possibility. Also, recent development of broad band split beam acoustics and ADCP are a promising tools for monitoring fish movements in relation to currents (Gordon, 1997).

Trawl Techniques. Survey trawls are normally adapted commercial trawls. The conflicting goals, i.e. the industry want a selective trawl catching the valuable fish while the scientist want a representative sample of the population in the area of trawling, underscore the potential inefficiency of many survey 
trawls to meet basic requirements. The great variety of survey trawls (every survey has its own trawl), is an additional impediment to utilization of available information on trawl-fish interactions to improve the design of survey of trawls. Improvements in survey trawl construction must be based on a long-term development program. Systematic studies from several countries using the same trawl are the best basis for trawl improvement. An example of such co-operation is the development and use of the North Sea bottom trawl by all North Sea countries (Anon., 1992). Also, Norway and Canada use the same trawl for cod in the Barents Sea and off Newfoundland, and Russian scientists are preparing to switch to the same trawl for their bottom trawl surveys in the Barents Sea. In such cases the potential for future improvements increases due to the possibility of drawing on a larger pool of information. Traditionally, changes in sampling equipment or procedures have been avoided in most bottom trawl surveys because of concern that changes would invalidate a survey time series. Recent achievements and new insight into the inefficiency of applied survey trawls worldwide (Engås, 1994; Walsh, MS 1997; Andrew et al., 1991; Somerton et al., 1997) have resulted in new sampling gears being employed in several areas. In such cases, the change has been preceded by calibration experiments so that the new data can be combined with the old (Godø and Sunnanå, 1992; Warren et al., MS 1997). Normally these experiments use side by side or alternating trawling to estimate the differences between the old and new equipment by species and size. In the future, improved methods for calibration are needed to secure rational and efficient changes.

Variability in trawl catches contribute strongly to the uncertainty of both trawl and acoustic surveys (Gunderson, 1993). Increasing the number of trawl stations is expensive and in most cases not realistic due to limited budgets. Shortening tow duration may improve survey efficiency substantially (Pennington and Vølstad, 1991). The possibility of using shorter tows (see Godø et al., 1990) can also be combined with new multi-sampling trawl techniques where several samples are taken during one tow (Engås et al.,

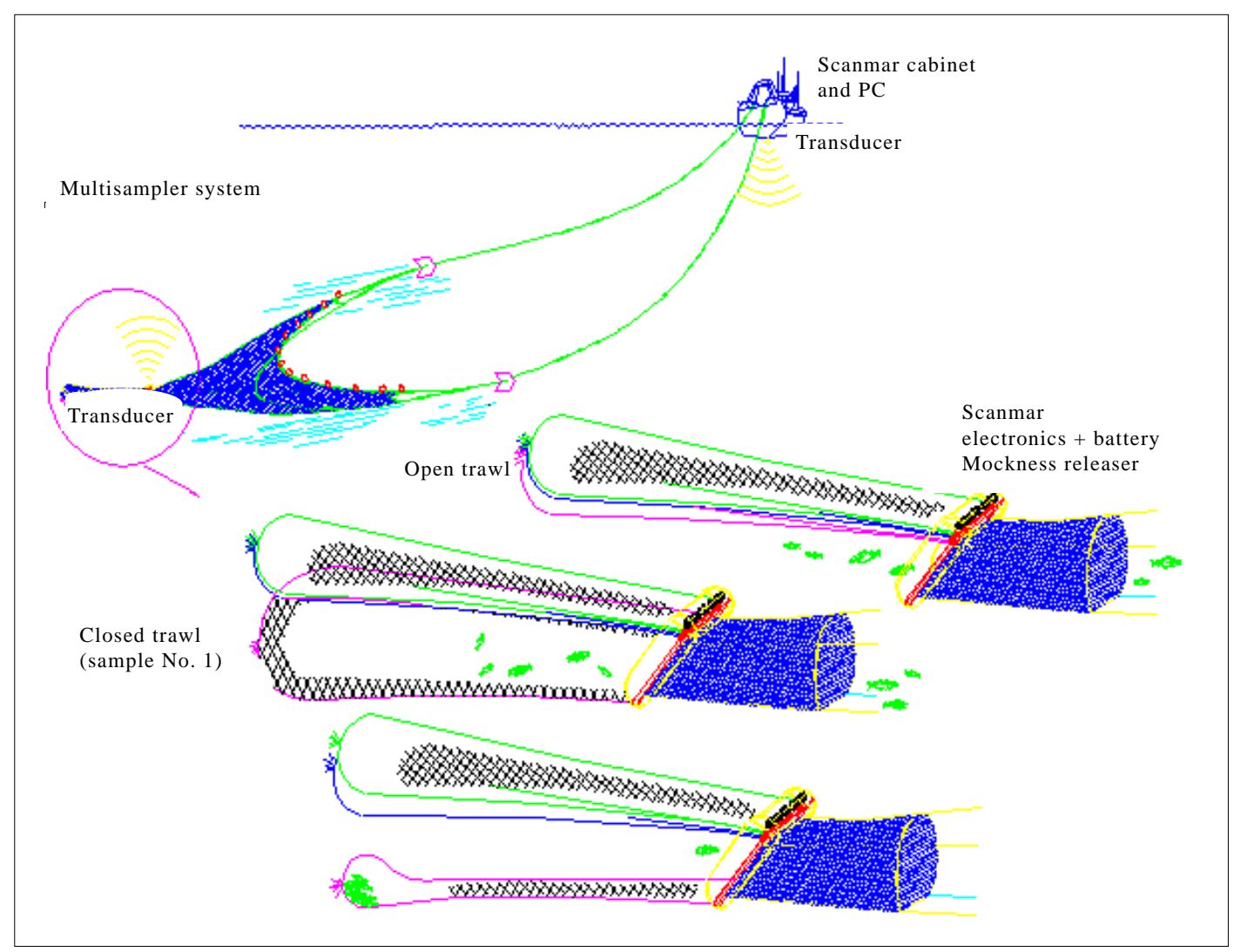

Fig. 11. The multisampler - a trawl arrangement allowing several samples to be taken during one haul. An acoustic link is used to open and close three individual cod-ends (Engås et al., 1996). 
1996, Fig. 11). This approach could fundamentally improve our understanding of small scale spatial distribution structure. The temporal resolution of trawl catches might be as important as the spatial distribution for many species due to the very high variation in both composition and size at one site over time (Michalsen et al., 1996, Godø et al., 1998). Repeated sampling through the temporal cycle (e.g. day and night) at selected locations might be an approach to isolate the temporal "noise" in the data. Such approaches could improve our measures of density and thus abundance.

Light and sound are known to affect fish behaviour strongly (see e.g. Wardle, 1993; Fernø and Olsen, 1994). Different types of devices are used in commercial fisheries to improve the efficiency of fishing gears, for example light to aggregate pelagic fish before setting purse seines (see Kristiansson, 1968). To my knowledge very few experiments have been done to improve sampling gear catchability. Light and sound are known to cause avoidance reactions by clupeoides and gadoids (Olsen et al., 1983; Freon et. al., 1993b; Ona and Godø, 1990; Nunnallee, MS 1991). When avoidance is toward the bottom, as found for many gadoids passed by a trawling vessel, this reaction pattern could, for example be intensified by towing additional sound sources strategically positioned behind the vessel.

It is known that fish may swim in front of a bottom sampling trawl for a substantial amount of time (Wardle, 1993). The longer fish occupy the trawl opening the greater their chance is of finding an escape path (see e.g. Walsh and Hickey, 1993). Disrupted performance by the trawl seems to break up any schooling fish in front of the vessel, which increases the turnover rate of the fish and hence reduces escapement (Godø, 1994, MS 1994; Aglen et al., MS 1997). Both visual and sound stimuli might be responsible for this phenomenon. Tests should be done to try to repeat this reaction pattern by generating disruptive movements by the gear during trawling. If the hypothesis is verified, the next question will be how to utilize this knowledge to improve sampling efficiency.

The continuous improvement of underwater observation techniques during the last decades has greatly contributed to information on fish and trawl behaviour and the interaction between them. Utilization of this information for improving trawl design and trawling techniques has been very limited. Future research must to a greater extent be co-ordinated and aimed towards getting complete and quantitative pictures of the dynamics of fish behaviour in the catching process. Dickson (1993a, b) integrated the available information on catch dynamics into a model in order to generate estimates of absolute abundance for cod and haddock. More exercises of this type are needed. However, such work is, at present, limited by the lack of ability of existing techniques to quantify observed fish behaviour under all conditions experienced during a survey. For example, what is the validity of data gathered under optimal light condition and on smooth bottom for modelling trawl efficiency under all conditions experienced during a survey?

\section{Commercial Catch Data}

The most direct measure of stock abundance in the past came from reliable records of landings. Due to difficulties in controlling the ever changing technology and strategy employed by the commercial fleet, catch and effort data are difficult to use for assessing the present state of a stock. Therefore, its importance has been reduced with the establishment of scientific surveys. However, modern communication technology has improved the possibility of getting quick and detailed data from the fishing grounds. I think that such a database could serve several applications. In Norway, it has been shown that the fishing power of each trawler in the fleet can be estimated with relatively high reliability. Thus, the catch data can be used to simulate surveys for example by month. Such simulations could be used for stock assessment purposes, and might possibly contribute information on fish migration and distribution. Also, a correct understanding of the underwater dynamics of heavily exploited fish stocks demands control and comprehension of the removal dynamics by man.

In addition, a continuous time series of CPUE indices could give valuable information on changes in catchability (see also Fig. 3). Scientific bottom trawl surveys assume constant catchability over time. If, for example, CPUE analyses show substantial relative changes between surveys, the survey data could be 
treated accordingly (Fig. 3). Also, if there is a known relationship between survey trawl and commercial trawl efficiency, this can be used to integrate the two types of data and thereby improve our understanding of seasonal population dynamics.

\section{Future of Stock Abundance Estimation by Observations From the Sea}

It appears that no particular technological development is underway which alone will solve all the problems of direct stock assessment from field observations. Nevertheless, the potential for improvement in assessments based on scientific observations has never been greater. Technology is the driving force, but it must be applied to cause a revolution. The advances in underwater observation technology has greatly improved our knowledge and understanding of the underwater reality. The performance and quality of applied sampling gears and procedures can now be critically examined and evaluated in relation to fish behaviour and distribution. While many of the observation methods are still imprecise with respect to quantification, they clearly have potential for assessment purposes in the future. We are now just on the threshold to a new 'world' of information. However, limited resources and expertise in fisheries research prevent its use and development.

Present methodologies of fish stock abundance estimation are characterized by:

- rigid standardization,

- isolation from auxiliary variables, and

- "Water proof" barriers hindering integration of methods and data obtained from different techniques.

The inability to observe the underwater reality in the past made this blindfolded approach rational and appeared to be the best way of reducing the effects of unknown variability. As far as I can see, current knowledge and technology and the expected new developments in observation techniques, can hardly be utilized efficiently under these three basic characteristics. Rigid standardization prevents implementation of new technology and information as well as full utilization of auxiliary variables. Our present ability to "see" has opened for us alternative approaches. I think that the "era of ignorance" (when decisions are based on not knowing) is over and we have entered the "era of knowledge" (decisions are based on knowing). Estimates from present surveys normally represent a fraction of a stock. If abundance estimates from surveys with different stock coverage are considered pieces in a puzzle, it should be possible to merge different sources of information to complete our perception of the status of the entire stock. For example if acoustic and bottom trawl survey data for gadoids (see Fig. 8) can be properly combined our perception of stock composition and development can potentially be substantially improve over time. What we need for the next century is a new approach that actively and systematically utilizes the new observational methods and their generated knowledge.

Under the new approach, better stock assessments can be obtained through new or improved observation tools and methods and/or by increasing the basic biological understanding and knowledge. What then will be the new survey characteristics?

In the past, a routine survey using state-of-the-art in observational methodologies was applied in a systematic and standardized manner to collect measures of fish stock densities. Rigid standardization at all levels, e.g. the bottom trawl, was to secure the integrity of long-term time series. There has been a firm resistance against change, although studies have clearly shown that the basic assumptions do not hold. Under the new approach, standardization will be aimed directly at biological characteristics instead of rigid statements on equipment and procedures.

As an example; for acoustic surveys, instrument improvements have been continuously implemented as they obviously improve the results. Proper calibration routines insure that such improvements will not invalidate the historical series but will improve the precision. 
Standardization of methods means that:

1. the gear operate physically in the same way in all conditions.

2. the gear sample the a target species and sizes with equal efficiency under all situations.

Point 1 is most critical for active sampling gears such as trawl and acoustic gear. It will be necessary to monitor performance, for example a sampling trawl with acoustic trawl instrumentation, to obtain a constant swept area. Instrumentation for monitoring bottom contact is critical for the standardization of sampling area and will probably soon be available. Bottom type can be monitored by acoustic instrumentation (e.g. RoxAnn http://www.stenmar.com/roxann.html, see e.g. Magorrian et al., 1995) to take this effect into account when analyzing the data. Changes in procedures and equipment are necessary when measurements show that the gear is not performing according to the standard because of unpredictable trawl geometry and performance. The use of trawl instrumentation to monitor trawl geometry and performance has become standard for many surveys. However, very few surveys have changed procedures and equipment to better meet the ideal standards.

For acoustic surveys, standard performance is secured through calibration (Foote et al., 1987). However, reduced performance can be caused by bad weather conditions and/or increasing depth. Technical improvements, for example by using a transducer mounted on a protruded platform, has proved to be a simple and effective solution. Increasing beam volume with depth reduces the reflected energy from small targets, i.e. the effective beam angle for varying fish sizes might vary (Ona, MS 1990). This can be compensated for if the actual size composition of the targets is known. Also, the vessel system can be calibrated for the effect of depth by using the output from a towed body or an AOV with the same sounder and transducer operating close to the acoustic targets.

As shown earlier, all known sampling methods are selective. When selection has been detected, two questions have to be considered. Firstly, can the selectivity be quantified and, secondly, can the sampling gear be changed or replaced to avoid or minimize the problem? If improved sampling gear is found, calibration (as in the acoustic survey) can be carried out to secure the integrity of the time series. Examples of such calibrations exist (Godø and Sunnanå, 1992; Warren et al., MS 1997).

Calibration studies will never be perfect. The results might be corrupted by the high variation caused by behaviour and environment factors. However, the effects of such variability have already invalidated the old time series. Corrections, based on calibration will certainly not improve the past, but the new and better sampling gear will improve future assessments based on the survey time series. Introduction of modest improvements in equipment or procedures can also be introduced over time, particularly when the goal is to reduce variability rather than increase efficiency.

Auxiliary variables will certainly in the future receive much more attention than they do today. Modern observation technology will facilitate the recordings of, for example temperature, light, bottom type, current strength and direction, etc., continuously during a survey. When fundamental studies on the effects these variables have on, for example swimming capacity, escape reactions, distribution and migration are available, their effect on survey efficiency can be determined.

In the evaluation of a stock's status, survey indices of abundance are used to tune a VPA or similar types of catch at age models (Hilborn and Walters, 1992). When several indices exist for the same stock, they often give conflicting signals on abundance trends and age composition because their observation windows are different (Fig. 1). Thus, the survey results lose importance in the assessment. To improve the utilization and effectiveness of such time series, we must develop methods and models that combine survey abundance data into one estimate of abundance before the data are used in assessments or as inputs for ecosystem models. With the increasing length of survey time series, the relative performance of surveys $v s$ catch-data based assessments should be ascertained. Such analysis will certainly with time increase the importance of surveys (see Pennington and Strømme, 1997). 
All the currently applied methods for obtaining biological information from the sea are biased and imprecise to a varying extent. It is pure fantasy to believe that observational methods in the near future are going to give precise and unbiased estimates and, hence, consistently reliable assessments of exploited fish stocks. The limitation of the present survey methodology is perhaps not low efficiency. The problem is rather that we try, with our standardized methods, to assess populations with non-standardized individual and collective behaviourial patterns. The way to more reliable observations from the sea is methods that collect and utilize new information on these behaviour patterns. This approach demand development of new technology and the application of existing technology from other fields (e.g. underwater oil exploitation). When this new fund of knowledge is utilized and integrated into assessments, our future management decisions will certainly become much more reliable than in the past.

\section{Acknowledgements}

Dr. M Pennington is thanked for his review and valuable discussions during the preparation of this manuscript. So are also many of my colleagues who have supplied material and ideas for this review.

\section{References}

AGLEN, A. 1994. Sources of error in acoustic estimation of fish abundance. In: Marine Fish Behaviour Related to Capture and Abundance Estimation. A. Fernø, and S. Olsen (eds.). Fishing News Books, Oxford, p. 107-133.

1996. Impact of fish distribution and species composition on the relationship between acoustic and sweptarea estimates of fish density. ICES J. Mar. Sci., 53: 501-506.

AGlen, A., A. ENGÅS, O. R. GODØ, B. MCCAlluM, D. STANSBURY, and S. J. WALSH. MS 1997. Density dependent catchability in bottom trawl surveys. ICES C.M. Doc., No. W16.

ALTON, M. 1986. A workshop on comparative biology, assessment, and management of gadoids from the North Pacific and Atlantic Oceans. Seattle, Washington, June, 1985, 1289 p.

ANDERSON, E. D. 1998. The history of fisheries management and scientific advice - the ICNAF/NAFO history from the end of World War II to the present. J. Northw. Atl. Sci., 23: 75-94 (this volume).

ANDREW, N. L., K. J. GRAHAM, S. J. KENNELLY, and M. K. BROADHURST. 1991. The effects of trawl configuration on the size and composition of catches using bentic prawn trawls off the New South Wales, Australia. ICES J. Mar. Sci., 48: 201-209.

ANON. MS 1959. Second progress report of the working group on Arctic Fisheries. Copenhagen, September 28October 4, 1959. ICES C.M. Doc., 64 p.

MS 1992. Manual for the international bottom trawl surveys. ICES C.M. Doc., No. H:3.

MS 1995. Report of the study group on target strength methodology. ICES C.M. Doc., No. B:3.

MS 1997. Report of the multispecies assessment working group. ICES C.M. Doc., No. Assess:16.

ARNOLD, G., B. LUNDGREN, and O. R. GODØ. 1995. Report of a workshop 'Electronic tags in fisheries research and management'. Sponsored in part by the European Commission AIR Programme and held at the Fisheries Laboratory, Lowestoft, UK 14-17 November 1994. Fisheries Laboratory, Lowestoft, UK.

ARNOLD, G. P. 1981. Movements of fish in relation to water currents. In: Animal migration. D. J. Aidley (ed.). Society for Experimental Biology Seminar Series 13. Cambridge University Press, Cambridge, p. 55-79.

BEAMISH, F. W. H. 1966. Vertical migration by demersal fish in the Northwest Atlantic. J. Fish. Res. Board Can., 23(1): 109-139.

BEVERTON, R. J. H., and S. J. HOLT. 1957. On the dynamics of exploited fish populations. Fish. Invest. Lond., Ser. II, 19: $533 \mathrm{p}$.

BOGSTAD, B., and S. TJELMELAND. 1993. The Barents Sea capelin stock collapse: a lesson to learn. In: Risk valuation and biological reference points for fisheries management. S. J. Smith, J. Hunt, and D. Rivard (eds.). Can. Spec. Publ. Fish. Aquat. Sci., 120: 127-142.

DAHM, E., and H. WIENBECK. MS 1992.Escapement of fish underneath the groundrope of a standard bottom trawl used for stock assessment purposes in the North sea. ICES C.M. Doc., No. B:20, 9 p.

DALEN, J., H. BODHOLT, and K. T. SOGN. 1995. Deep-water towed vehicle with optical fibre in tow-cable. ICES Int. Symp. on Fisheries and Plankton Acoustics, Aberdeen (UK), 12-16 Jun, 1995.

DICKSON, W. 1993a. Estimation of capture efficiency of trawl gear. I: Development of a theoretical model. Fish. Res., 16: 239-253.

1993b. Estimation of capture efficiency of trawl gear. II: Testing a theoretical model. Fish. Res., 16: 255-272.

DOUBledAY, W. G., and D. RIVARD. 1981. Bottom trawl surveys. Can. Spec. Publ. Fish. Aquat Sci., 58: 1-273.

DRAGESUND, O., and S. OLSEN. 1965. On the possibility of estimating year-class strength by measuring cho abundance of 0-group fish. Fiskeridir. Skr. Havunders., 13(8): 47-71. 
ENGÅS, A. 1994. The effects of trawl performance and fish behaviour on the catching efficiency of demersal sampling trawls. In: Marine Fish Behaviour Related to Capture and Abundance Estimation. (A. Fern $\varnothing$ and S. Olsen (eds.). Fishing News Books, Oxford, p. 45-68.

ENGÅS, A., and O. R. GODØ. 1986. Influence of trawl geometry and vertical distribution of fish on sampling with bottom trawl. J. Northw. Atl. Fish. Sci., 7: 35-42.

1989a. Escape of fish under the fishing line of a Norwegian sampling trawl and its influence on survey results. ICES J. Cons., 45: 269-276.

1989b. The effect of different sweeps on length composition of bottom sampling trawl catches. ICES J. Cons., 45: 263-268.

ENGÅS, A., and T. JØRGENSEN. MS 1997. The probability of cod (Gadus morhua) and ling (Molva molva) to encounter gillnet based on in situ fish movements. ICES C.M. Doc., No. W:17.

ENGÅS, A., and S. LØKKEBORG. 1994. Abundance estimation using gillnet and longline - the role of fish behaviour. In: Marine Fish Behaviour Related to Capture and Abundance Estimation. A. Fern $\varnothing$, and S. Olsen (eds.). Fishing News Books, Oxford, p. 134-165.

ENGÅS, A., and E. ONA. MS 1991. A method to reduce survey bottom trawl variability. ICES C.M. Doc., No. B:39. MS 1993. Experiences using the constraint technique on bottom trawl doors. ICES C.M. Doc., No. B:18, $6 \mathrm{p}$.

ENGÅS, A, and A. V. SOLDAL. 1992. Diurnal variation in trawl catch rates of cod and haddock and their influence on abundance indices. ICES J. Mar. Sci., 49: 89-95.

ENGÅS, A., R. SKEIDE, and C. M. WEST. 1996. The multisampler: a system for remotely opening and closing multiple codends on a sampling trawl. Fish. Res., 29: 295-298.

ERICH, S. MS 1987. The portion of young cod escaping under the G.O.V.-trawl rigged with a heavy bobbin footrope. ICES C.M. Doc., No. B:15.

FAO. 1995a. Precautionary approach to fisheries. Part 1: Guidelines on the precautionary approach to capture fisheries and species introduction. FAO Fish. Tech. Pap., 350(1): 1-52.

1995b. Precautionary approach to fisheries. Part 2: Scientific papers. FAO Fish. Tech. Pap., 350(2): 1-210. 1997. The state of world fisheries and acquaculture, 1996. ISSN 1020-5489. FAO, 1997.

FERNØ, A., and S. OLSEN (eds.). 1994. Marine fish behaviour related to capture and abundance estimation. Fishing News Books, Oxford.

FOOTE, K., H. P. KNUDSEN, G. VESTNES, D. N. MACLENNAN, and E. J. SIMMONDS. 1987. Calibration of acoustic instruments for fish density estimation: a practical guide. ICES Coop. Res. Rep., 144.

FOOTE, K., and G. STEFANSSON. 1993. Definition of the problem of estimating fish abundance over an area from acoustic line-transect measurements of density. ICES J. Mar. Sci., 50: 369-381.

FOOTE, K., H. P. KNUDSEN, R. KORNELIUSSEN, P. E. NORDBØ, and K. RØANG. 1991. Postprocessing system for echo integrator data. J. Acoust. Soc. Am., 90: 37-47.

FREON, P., M. SORIA, C. MULLON, and F. GERLOTTO. 1993a. Diurnal variation in fish density estimates during acoustic surveys in relation to spatial distribution and avoidance reaction. Aquat. Liv. Res., 61: 221-234.

FREON, P., F. GERLOTTO, and M. SORIA. 1993b. Variability of Harengula sp. school reactions to boats or predators in shallow water. ICES Mar. Sci. Symp., 196: 30-35.

FULTON, T. W. 1898. Review of the trawling experiments of the "Garland" in the Firth of Forth and St Andrews Bay in the years 1886-1895. Rep. Fish. Board. Scot., 14 (Part II Scientific investigation): 128-149.

GJEVIK, B., E. NØST, and T. STRAUME. 1994. Model simulations of the tides in the Barents Sea. J. Geophys. Res., 99: $3337-3350$

GLASS, C. W., and C. S. WARDLE. 1989. Comparison of the reaction of fish to trawl gear, at high and low light intensities. Fish. Res., 7: 249-266.

GODØ, O. R. 1994. Factors affecting reliability of abundance estimates of ground fish from bottom trawl surveys. In: Marine Fish Behaviour Related to Capture and Abundance Estimation. A. Fern $\varnothing$, and S. Olsen (eds.). Fishing News Books, Oxford, p. 166-199.

MS 1994. Natural fish behaviour and catchability of groundfish. ICES C.M. Doc., No. B:14, 11 p.

GODØ, O.R., and A. ENGÅS. 1989. Swept area variation with depth and its influence on abundance indices of groundfish from trawl surveys. J. Northw. Atl. Fish. Atl. Fish. Sci., 9: 133-139.

GODØ, O. R., and K. MICHALSEN. MS 1997. The use of data storage tags to study cod natural behaviour and availability to abundance surveys in the Barents Sea. ICES C.M. Doc., No. W:18, 23 p.

GODØ, O. R., and K. SUNNANÅ. 1992. Size selection during trawl sampling of cod and haddock and its effect on abundance indices at age. Fish. Res., 13: 293-310.

GODØ, O. R., and A. TOTLAND. MS 1996. A stationary acoustic system for monitoring undisturbed and vessel affected fish behaviour. ICES C.M. Doc., No. B:12, 11 p.

GODØ, O. R., and S. WALSH. 1992. Escapement of fish during trawl sampling - implication of resource assessment. Fish. Res., 13: 281-292.

GODØ, O. R., and V. G. WESPESTAD. 1993. Monitoring changes in abundance of gadoids with varying availability 
to trawl and acoustic surveys. ICES J. Mar. Sci., 50: 39-51.

GODØ, O. R., M. PENNINGTON, and J. H. VØLSTAD. 1990. Effect of tow duration on length composition of trawl catches. Fish. Res., 9: 165-179.

GODØ, O. R., I. HUSE, and K. MICHALSEN. 1997. Bait defence behaviour of wolffish and its impact on long-line catch rates. ICES J. Mar. Sci., 54: 273-275.

GODØ, O. R., W. KARP, and A. TOTLAND. 1998. Effects of trawl sampling variability on precision of abundance estimates of gadoids from the Barents and Sea and the Gulf of Alaska. ICES J. Mar. Sci., 55: 86-94.

GORDON, L. 1997. FishMASS: Fish Monitoring Acoustic Sensing System. ICES WG on fisheries acoustics science and technology. Hamburg, April, 1997.

GUNDERSON, D. R. 1993. Surveys of fisheries resources. John Wiley \& Sons, Inc., New York, 248 p.

GUNN, J., T. POLACHECK, T. DAVIS, M. SHERLOCK, and A. BETLEHEM. MS 1994. The development and use of archival tags for studying the migration, behaviour and physiology of southern bluefin tuna, with an assessment of the potential for transfer of the technology to groundfish research. ICES C.M. Doc., No. 21,21 p.

HILBORN, R., and C. J. WALTERS. 1992. Quantitative fisheries stock assessment: choice, dynamics and uncertainty. Chapman and Hall, New York, 570 p.

HJORT, J. 1914. Fluctuation in the great fisheries of Northern Europe. Viewed in the light of biological research. ICES Rapp. Proc.-Verb., 20: 1-226.

HUSE, I., and E. ONA. 1996. Tilt angle distribution and swimming speed of overwintering Norwegian spring spawning herring. ICES J. Mar. Sci., 53: 863-873.

HOVGÅRD, H., and F. F. RIGET. 1992. Comparison of longline and trawl selectivity in cod surveys off West Greenland. Fish. Res., 13: 323-334.

JAKOBSSON, J., O. ASTTHORSSON, R. J. H. BEVERTON, B. BJØRNSSON, N. DAAN, K. FRANK, J. MEINCKE, B. ROTHSCHILD, S. SUNDBY, and S. TILSETH. Cod and climate change. ICES Mar. Sci. Symp., 198: 1-693.

JOHANNESSON, K. A., and R. B. MITSON. 1983. Fisheries acoustics - A practical manual for aquatic biomass estimation. FAO Fish. Tech. Pap., 240: 1-249.

KARP, W. A., and G. E. WALTERS. 1994. Survey assessment of semi-pelagic gadoids: The example of Walleye Pollock, Theragra chalcogramma, in the Eastern Bering Sea. Mar. Fisheries Review, 56(1): 8-22.

KOELLER, P. A. 1991. Approaches to improving groundfish survey abundance estimates by controlling the variability of survey gear geometry and performance. J. Northw. Atl. Fish. Sci., 11: 51-58.

KRISTJANSSON, H. 1968. Modern fishing gear of the world. Fishing News Books, Ltd., London, 610 p.

LAEVASTU, T., and H. A. LARKINS. 1981. Marine fisheries ecosystem. Fishing News Books Ltd., Farnham, 162 p.

MacLENNAN, D. N., and E. J. SIMMONS. 1991. Fisheries acoustics. Chapman Hall, London, 336 p.

MAGORRIAN, B. H., M. SERVICE, and W. CLARKE. 1995. An acoustic bottom classification survey of Strangford Lough, Northern Ireland. J. Mar. Biol., 754: 987-992.

MAIN, J., and G. I. SANGSTER. 1981. A study of the fish capture process in a bottom trawl by direct observations from an underwater vehicle. Scott. Fish. Res. Rep., 23, 23 p.

MASSÉ, J., and N. RETIÈRE. 1995. Effect of number of transects and identification hauls on acoustic biomass estimates under mixed species conditions. Aquat. Liv. Res., 82: 195-199.

MEHL, S., and O. NAKKEN. 1996. Botnfiskundersøkingar i Barentshavet vinteren, 1996 (Investigation on demersal fish in the Barents Sea winter, 1996). Fisken og Havet, 11: 1-68.

METCALFE, J. D., B. H. HOLFORD, and G. P. ARNOLD. 1993. Orientation of plaice (Pleuroectes platessa) in the open sea: evidence for the use of external directional clues. Mar. Biol., 117: 559-566.

METCALFE, J. D., G. P. ARNOLD, and B. H. HOLFORD. MS 1994. The migratory behaviour of plaice in the North Sea as revealed by data storage tags. ICES C.M. Doc., No. M11, 13 p.

MICHALSEN, K., O. R. GODØ, and A. FERNØ. 1996. Diel variation in the catchability of gadoids and its influence on the reliability of abundance indices. ICES J. Mar. Sci., 53: 389-395.

MISUND, O. A. 1994. Swimming behaviour of fish schools in connection with capture by purse seine and pelagic trawl. In: Marine Fish Behaviour Related to Capture and Abundance Estimation. A. Fern $\varnothing$ and S. Olsen (eds.). Fishing News Books, Oxford, p. 84-106.

Misund, O. A., A. AGLEN, J. HAMRE, E. ONA, I. RØTTINGEN, D. SKAGEN, and J. W. VALDEMARSEN. 1996. Improved mapping of schooling fish near the surface: comparison of abundance estimates obtained by sonarand echo integration. ICES J. Mar. Sci., 53: 383-388.

NUNNALLEE, E. MS 1991. An investigation of the avoidance reaction of Pacific whiting (Merluccius productus) for demersal and midwater trawl gear. ICES C.M. Doc., No. B:5.

OLSEN, K., J. ANGEL, F. PETTERSEN, and A. LØVIK. 1983. Observed fish reaction to a surveying vessel with special reference to herring, cod, capelin and polar cod. In: Symposium on Fisheries Acoustics. O. Nakken and S. C. Venema (eds.). Selected papers of the ICES/FAO Symposium on Fisheries Acoustics. Bergen, Norway, 2124 June, 1982. FAO Fish. Rep., 300: 131-138.

ONA, E. 1990. Physiological factors causing natural variations in acoustic target strength of fish. J. Mar. Biol. Assoc., 
70(1): $107-127$.

MS 1990. Optimal acoustic beam pattern corrections for split beam transducers. ICES C.M. Doc., No. B:30, $12 \mathrm{p}$.

1994. Recent Developments of acoustic instrumentation in connection with fish capture and abundance estimation. In: Marine Fish Behaviour Related to Capture and Abundance Estimation. A. Fern $\varnothing$, and S. Olsen (eds.) Fishing News Books, Oxford, p. 200-216.

ONA, E., and O. R. GODØ. 1990. Fish reaction to trawling noise: the significance for trawl sampling. ICES Rapp. Proc.-Verb., 189: 159-166.

ONA, E., and R. B. MITSON. 1996. Acoustic sampling and signal processing near the seabed: the dead zone revisited. ICES J. Mar. Sci., 53: 677-690.

ONA, E., and J. TRAYNOR. MS 1990. Hull mounted, protruding transducer for improving echo integration in bad weather. ICES C.M. Doc., No. B:31.

ONA, E., and R. TORESEN. MS 1988. Reaction of herring to trawling noise. ICES C.M. Doc., No. B:36.

PARRISH, B. B., J. H. S. BLAXTER, and W. B. HALL. 1964. Diurnal variation in size and composition of trawl catches. ICES Rapp. Proc.-Verb., 155: 27-34.

PAULY, D. 1988. Fisheries research and the demersal fisheries of Southeast Asia. In: Fish Population Dynamics (Second edition). J. A. Gulland (ed.). John Wiley \& Sons Ltd., Chichester, p. 329-362.

PENNINGTON, M., and J. H. VØLSTAD. 1991. Optimum size of sampling unit for estimating the density of marine populations. Biometrics, 47: 717-723.

PENNINGTON, M., and T. STRØMME. 1998. Survey as a research tool for managing dynamic stocks. Fish. Res., (in press).

QUIN, T. J., R. B. DERIOSO, and S. H. HOAG. 1985. Methods of Population Assessment of Pacific Halibut. International Pacific Halibut Commission, Seattle, WA, Scientific Report 72.

ROBINSON, S. M. C., J. D. MARTIN, R. A. CHANDLER, and G. J. A. PARSONS. 1991. A video assessment of a large mortality event in a population of the sea scallop, Placopecten magellanicus, in the Bay of Fundy, Canada. J. Shell. Res., 10(1): 1-283.

ROSE, C. S., and G. E. WALTERS. 1990. Trawl width variation during bottom trawl surveys: Causes and consequences. Int. North. Pac. Fish. Comm. Bull., 50: 57-67.

ROSE, G. A., D. B. ATKINSON, J. BAIRD, C. A. BISHOP, and D. W. KULKA. 1994. Changes in distribution of Atlantic cod and thermal variations in Newfoundland Waters, 1980-1992. ICES Mar. Sci. Symp., 198: 542-552.

SAINSBURY, K. J. 1988. The ecological basis of multispecies fisheries, and management of a demersal fishery in tropical in tropical Australia. In: Fish Population Dynamics (Second edition). J. A. Gulland (ed.). John Wiley \& Sons Ltd., Chichester, p. 349-382.

SIMMONDS and MacLENNAN. 1996.

SIMMONDS, E. J., N. J. WILLIAMSON, F. GERLOTTO, and A. AGLEN. 1992. Acoustic survey design and analysis procedure: A comprehensive review of current practice. ICES Coop. Res. Rep., 187: 1-127.

SOMERTON, D. A., and B. S. KIKKAWA. 1995. A stock survey technique using the time to capture individual fish on longlines. Can. J. Fish. Aquat. Sci., 52: 1-11.

SOMERTON, D., J. IANELLI, S. WALSH, S. SMITH, O. R. GODØ, and D. RAMM. MS 1997. Incorporating experimentally derived estimates of survey trawl catchability into stock assessment process. ICES C.M. Doc., No. W: 05.

STØRKERSEN, N., H. HENRIKSEN, and R. A. KLEPAKER. 1996. Acoustically controlled untethered vehicle system for deep water seabed mapping. In: Proceedings of the 6th International Offshore and Polar Conference, vol II, Los Angeles, USA, p. 251-255.

ULLTANG, Ø. 1977. Sources of errors in and limitations of Virtual Population Analysis (Cohort analysis). ICES J. Cons., 37(3): 249-260.

UNCED. 1992. Rio Declaration on Environment and Development. Conf.151/26 (Vol. I).

WALSH, S. 1988. Diel variability in trawl catches of juveniles and adult yellowtail flounder on the Grand Banks and the effect on assessment. N. Amer. J. Fish. Man., 8: 373-381.

1991. Diel variation in availability of and vulnerability of fish to a survey trawl. J. Appl. Ichtyol., 7: 147-159.

1992a. Size-dependent selection at the footgear of a groundfish survey trawl. N. Amer. J. Fish. Man., 12(3): $625-633$.

1992b. Factors influencing distribution of juvenile yellowtail flounder (Limanda ferrugenea) on the Grand Bank off Newfoundland. Neth. J. Sea. Res., 15: 250-272.

MS 1997. Performance of mobile and static gears used in single and multi-species resource surveys: a review. ICES C.M. Doc., No. W:02.

WALSH, S. J., and W. M. HICKEY. 1993. Behavioural reactions of demersal fish to bottom trawls at various light conditions. ICES Mar. Sci. Symp., 196: 68-76.

WALSH, S., P. A. KOELLER, and W. D. MCKONE. 1993. Proceedings of the international workshop on survey 
trawl mensuration, Northwest Atlantic Fisheries Centre, St. John's, Newfoundland, March 18-19, 1991. Can. Tech. Rep. Fish. Aquat. Sci., 1911: iv + 114 pp.

WARDLE, C. S. 1993. Fish behaviour and fishing gear. In: Behaviour of Teleost Fishes. T.J. Pitcher (ed.). Chapmann \& Hall, London, p. 609-643.

WARREN, W., W. BRODIE, D. STANSBURY, S. WALSH, J. MORGAN, and D. ORR. MS 1997. Analysis of the 1996 comparative fishing trial between the Alfred Needler with the Engel 145 trawl and the Wilfred Templeman with the Campelen 1800 trawl. NAFO SCR. Doc., No. 68, Serial No. N2902, 12 p.

WEINBERG, K., and P. T. MUNRO. MS 1997. The effect of artificial light on escapement beneath A survey trawl. ICES C.M.Doc., No. W/07, 15 p.

WEST, M. B. 1998. The future of the international law of capture fisheries. J. Northw. Atl. Fish. Sci., 23: 19-25 (this volume).

ZAFERMAN, M. L. 1979. Methods of instrument assessment of the bottom fish abundance. Meeting on hydroacoustical methods for the estimation of marine fish populations, 25-29 June, 1979. Vol II, Part b. The Charles Stark Draper Lab. Inc., Cambridge, Mass., USA, 895-906.

1997. New underwater TV methods and equipment for observations over marine organisms. Joint Russian Norwegian Symposium on Gear Selection and Sampling Gears. June 22-23, 1997. Murmansk, Russia.

ZHAO, X. 1996. Target strength of herring (Clupea harengus L.) measured by split-beam tracking method. M.Phil. thesis. Department of Fisheries and Marine Biology. University of Bergen, 103 p. 
